\title{
Sequential Synthesis, Olfactory Properties, and Biological Activity of Quinoxaline Derivatives
}

\author{
Mia Imanishi, ${ }^{\dagger}$ Motohiro Sonoda, ${ }^{\dagger}$ Hironari Miyazato, ${ }^{\ddagger}$ Keiichiro Sugimoto, ${ }^{\ddagger}$ Mitsugu Akagawa, ${ }^{\dagger}$ \\ and Shinji Tanimori*, ${ }^{\dagger}$ \\ ${ }^{\dagger}$ Department of Applied Biosciences, Graduate School of Life and Environmental Sciences, Osaka Prefecture University, 1-1 \\ Gakuencho, Nakaku, Sakai, Osaka 599-8241, Japan \\ ${ }^{\ddagger}$ Research and Development Center, Nagaoka Co., Ltd., 1-3-30 Itsukaichi, Ibaraki, Osaka 567-0005, Japan
}

Supporting Information

ABSTRACT: A simple, practical, and rapid access to quinoxalin-2-ones 1, 1,2,3,4-tetrahydroquinoxalines 2, quinoxalines 3 , and quinoxalin-2 $(1 H)$-ones 4 has been achieved, based on the copper-catalyzed quinoxalinone formation of 2haloanilines and amino acids followed by their reduction and oxidation. The olfactory properties and lipid accumulation inhibitory activity in cultured hepatocytes of the quinoxaline derivatives were also evaluated.
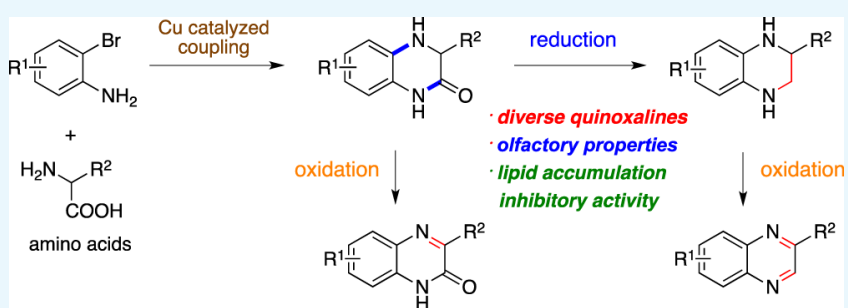

\section{INTRODUCTION}

Quinoxaline and its derivatives are important structural units for the development of pharmaceuticals, agrochemicals, and functional materials (Figure 1). ${ }^{1}$ Some quinoxalines also have a pleasant smell and savory properties. ${ }^{2}$ For instance, 5methylquinoxaline is not only identified by its roasted coffee flavor but also displays a nutty-type odor with a high odor intensity and is utilized for a series of food products, such as coffee, nuts, meats, and cocoa. ${ }^{2}$ Similarly, 2-methylquinoxaline has been identified in roasted coffee. However, reports on the odors of quinoxaline derivatives are still limited, ${ }^{2 c}$ and, therefore, the odors of many quinoxaline derivatives are unknown. Moreover, quinoxaline derivatives are known to display a diverse range of biological activities. ${ }^{1}$ On the basis of recent reports, ${ }^{3-5}$ we predicted that the quinoxaline derivatives may exert a liver-protective effect. Regarding the synthesis of the quinoxaline derivatives, a significant amount of literature dealing with the synthesis of quinoxaline derivatives has been published. ${ }^{1 \mathrm{a}, 6}$ We previously reported the synthesis of quinoxalin-2-ones 1 starting from 2-haloanilines and amino acids in the presence of a copper catalyst. ${ }^{7}$ It was anticipated that a series of quinoxaline congeners would be derived from the quinoxalin-2-ones $\mathbf{1}$ by employing simple manipulations such as reductions and oxidations (Scheme 1). In this report, we demonstrate the synthesis of a series of quinoxaline derivatives with different oxidation states, which include 1,2,3,4-tetrahydroquinoxalines 2 , quinoxalines 3 , and quinoxalin-2(1H)-ones 4 from quinoxalin-2-ones 1 . Their olfactory properties and hepatic lipid accumulation inhibitory activity using lipid-overloaded HepG2 hepatocytes were also evaluated.

\section{RESULTS AND DISCUSSION}

Synthesis. The syntheses of quinoxalinones were performed based on our previously reported procedure. ${ }^{7}$ The reactions of 2-bromoanilines with $\alpha$-amino acids in the presence of catalytic amounts of $\mathrm{CuCl}$ (5 mol \%), DMEDA (40 mol \%), and $\mathrm{K}_{3} \mathrm{PO}_{4}$ (2 equiv) afforded the desired quinoxalinones $\mathbf{1}$ in moderate to excellent yields (Table 1 ). Quinoxalinones 1a, 1b, and $1 \mathbf{k}$ were synthesized for the first time in this study. When 2-bromo-4,6-dimethylaniline was utilized as a substrate, 1,2-dihydroquinoxaline $1 \mathbf{k}$ was produced instead of the corresponding desired quinoxalinone.

The conversions of quinoxalinones 1 to 1,2,3,4-tetrahydroquinoxalines $\mathbf{2}$ were smoothly conducted using excess lithium aluminum hydride as the reducing agent (Table 2). ${ }^{8}$

The quinoxaline derivatives 3 were obtained by the oxidations of 1,2,3,4-tetrahydroquinoxalines 2 with vanadium (V) oxide. ${ }^{9}$ When (1,2,3,4-tetrahydroquinoxalin-2-yl)methanol $2 \mathbf{j}$ was applied under these conditions, aldehyde $3 \mathbf{j}$ was obtained in $11 \%$ yield. The $N$-methyl substrate $2 \mathbf{i}$ did not afford 1-methyl-1,2-dihydroquinoxaline $3 \mathbf{i}$.

The pathway to quinoxalin-2(1H)-one has been demonstrated using quinoxalinones $\mathbf{1 a}$ and $\mathbf{1 c}$ as model substrates (Scheme 2). Oxidation of quinoxalinones $1 \mathrm{a}$ and $1 \mathrm{c}$ with $\mathrm{V}_{2} \mathrm{O}_{5}$ provided quinoxalin-2(1H)-one $4 \mathrm{a}$ and $4 \mathrm{c}$ in 67 and $68 \%$ yields, respectively. Unfortunately, the reductions of $4 a$ and $4 c$ to the corresponding 1,2-dihydroquinoxalines have not been successful.

Olfactory Properties. We next evaluated the olfactory properties of the quinoxaline derivatives 1-3 synthesized in this study, which were performed by five panelists (30-50-yearold men), including three flavorists, by direct smelling from a sample tube. The results are listed in Table 1-3 under the structures of the compounds. Quinoxalines $3 a-c$ and $3 e$ were

Received: February 4, 2017

Accepted: April 20, 2017

Published: May 8, 2017 
<smiles>COc1cccc(-c2nc3cc(C(=O)NCCCNC=N)ccc3nc2N2CCOCC2)c1</smiles>

NAMPT inhibitor<smiles>Cc1cnccc1-c1cnc2cc(C(F)(F)F)ccc2n1</smiles>

pest control agent<smiles>CC1CC(=O)NN=C1c1ccc2nc(/C=C/Br)c(/C=C/Br)nc2c1</smiles>

organic light-emitting materials<smiles>Cc1cccc2nccnc12</smiles>

5-methylquinoxaline food flavor

Figure 1. Examples of useful quinoxaline derivatives.

Scheme 1. Synthetic Approach for Quinoxalinones 1, 1,2,3,4-Tetrahydroquinoxalines 2, Quinoxalines 3, and Quinoxalin-2(1H)ones 4<smiles>[R2]C(N)C(=O)OCC(=O)O</smiles><smiles></smiles>

1<smiles></smiles>

4<smiles></smiles>

oxidation<smiles>[R]c1cnc2ccncc2n1</smiles>

3 discovered in nature ${ }^{2}$ and their olfactory properties are already known; however, the other derivatives were evaluated for the first time. It was found that quinoxalinones $\mathbf{1}$ tended to have phenolic or medicine-like odors, although some of them have chocolate- (1e and $\mathbf{1 j}$ ) or cacaolike (1f) smells. We assume that this would be the case because of the existence of a carbonyl group on the quinoxalinones 1 . Some 1,2,3,4-tetrahydroquinoxalines $\mathbf{2}$ had odors of food such as nutty $(\mathbf{2 a})$ and roasty $(\mathbf{2 b}$ and $\mathbf{2 e}$ ). Others had phenolic (2c and $\mathbf{2 g}$ ), medicine-like (2d, $\mathbf{2 f}$, and $\mathbf{2 m}$ ), and fishy (2k) odors. Their odor qualities depended on the number and position of the substituents and also their functional groups. Generally, many 1,2,3,4-tetrahydroquinoxalines have a pungent odor. Gratifyingly, the monomethyl-substituted quinoxalines have desirable odors, such as coffeelike $(\mathbf{3 c})$, cookielike $(\mathbf{3 b})$, and roast chestnutlike (3e). On the other hand, the dimethyl, ethyl, and formylsubstituted quinoxalines displayed a phenolic (3d, $\mathbf{3 g}$, and $3 \mathbf{j}$ ) and smoky odor (3f). Generally, quinoxalines 3 did not display a pungent odor and had mild and desirable incenses. In terms of each quinoxaline derivative, roasty (2a), peanutlike (2e), cookielike $(3 \mathbf{b})$, coffeelike $(3 \mathbf{c})$, and roast chestnutlike odors (3e) have been determined. These compounds have common structural units such as being monomethyl substituted, especially, the 5-methyl-substituted quinoxaline. The intensity levels of the odors of the quinoxaline derivatives synthesized in this study were found to be as follows: quinoxalines $3>$ tetrahydroquinoxalines $\mathbf{2}>$ quinoxalinones $\mathbf{1}$.

Biological Activities. Recent research evidence has demonstrated that the cannabinoid type 2 (CB2) receptor has therapeutic value in terms of pain relief, inflammation, osteoporosis, treating cancers, and hepatoprotection. The activation of the CB2 receptors in Kupffer cells and hepatocytes has been reported to protect inflammatory liver injury and attenuate liver steatosis in vitro and in vivo. ${ }^{3-5}$ In recent years, structurally diverse CB2-selective agonists exhibiting an analgesic activity in various pain models have been discovered, and Saari et al. have reported that the quinoxaline derivatives showed a low-potency partial CB2 receptor agonist activity. ${ }^{3}$ Therefore, we predicted that the synthesized quinoxaline derivatives may exert a liver-protective effect. We screened the synthesized quinoxaline derivatives for lipid accumulation inhibitory activity using lipid-overloaded HepG2 hepatocytes. ${ }^{5}$ The cells were exposed to $0.5 \mathrm{mM}$ palmitate in the presence of each synthesized quinoxaline derivative for $24 \mathrm{~h}$; then the intracellular neutral lipids were determined by Oil Red $\mathrm{O}$ staining. As shown in Figure 2A, we found that some quinoxalinones 1 effectively prevent palmitate-induced lipid accumulation in HepG2 hepatocytes. It is noteworthy that 8methyl-3,4-dihydro-1H-quinoxalin-2-one (1a) and 3,6-dimethyl-3,4-dihydro-1H-quinoxalin-2-one (1f, 1m) showed a marked decrease in lipid accumulation by about $50 \%$ compared to that of the vehicle-treated control. In addition, tetrahydroquinoxalines $\mathbf{2 a}, \mathbf{2 e}, \mathbf{2} \mathbf{i}$, and quinoxalines $\mathbf{3 c}$ and $\mathbf{3 f}$ slightly inhibited the hepatic lipid accumulation (Figure 2B,C). These results suggest that the quinoxalinone structure might play a potential role in lipid accumulation suppressing activity, and some flavors might act as biofunctional materials. In future, further studies are needed to examine the detailed molecular mechanism underlying their actions, including CB2 agonistic activity and assess their in vivo efficacy.

\section{CONCLUSIONS}

In conclusion, a protocol for synthesizing a series of quinoxaline derivatives, that is, the 3,4-dihydroquinoxalin-2( $1 H)$-ones, quinoxalin-2(1H)-ones, 1,2,3,4-tetrahydroquinoxalines, and quinoxalines, varying in their four different oxidation states but with the same carbon skeleton, has been developed from readily available starting materials. These methods would serve the purposes of the fine tuning of odorants as well as the biological activities of pharmaceuticals and agrochemicals and also the functions of materials with the quinoxaline skeleton. Indeed, promising perfume and drug candidates among the 
Table 1. Synthesis of Quinoxalinones and Their Olfactory Properties

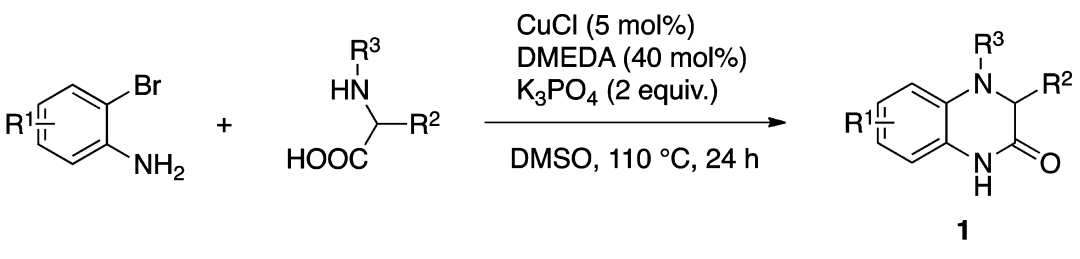

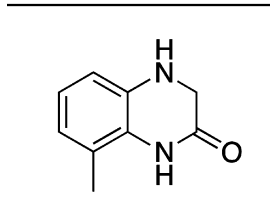

1a: $56 \%$

smoky, phenolic acidic, cacao nibs, bread, green soy bean, rubber<smiles>Cc1ccc2c(c1)N[C@H](C)C(=O)N2</smiles>

1f: $81 \%$

acidic, cacao, medicine, wet wood<smiles>Cc1cc(C)c2[nH]c(=O)cnc2c1</smiles>

1k: $63 \%$

phenolic, aldehydic, fish meal, ginseng, herbal medicine<smiles>Cc1ccc2c(c1)NCC(=O)N2</smiles>

1b: $83 \%$

rubber, plastic, smoky<smiles>CC1Nc2ccccc2NC1=O</smiles>

1c: $87 \%$

acidic, rubber, amine, bouillon<smiles>CCC1Nc2ccccc2NC1=O</smiles>

1d: $98 \%$

fenugreek, burnt sugar, curry powder. roasted soybean flour<smiles>Cc1cccc2c1NC(=O)[C@H](C)N2</smiles>

1e: $71 \%$

medicine, phenolic cresol, indole, chocolate, roasted soybean flour, dryness<smiles>CN1CC(=O)Nc2ccccc21</smiles>

1i: $66 \%$

amine, fishy, shrimp, crab, wet, cacao powder<smiles>O=C1Nc2ccccc2NC1CO</smiles>

1j: $48 \%$

smoky,chocolate, cacao, phenolic, solvent, adhesive crayon plastic, pyridine,
white smoke<smiles>C[C@@H]1Nc2ccccc2NC1=O</smiles>

1I: $87 \%$

rubber, phenolic, medicine<smiles>Cc1ccc2c(c1)N[C@H](C)C(=O)N2</smiles>

1m: $86 \%$

acidic, phenolic, nutty, yeast, flour<smiles>Cc1cccc2c1NC(=O)[C@H](C)N2</smiles>

1n: $70 \%$

pyridine, phenolic, smoky, medicine, corn, salmon, sesame synthetic quinoxaline derivatives obtained in this study have been observed in some cases. Studies for synthesizing other quinoxaline derivatives from 2-haloanilines and amino acids and a wide range of pharmaceutical and agrochemical activities for the synthetic quinoxalines are now under investigation and will be reported in due course.

\section{MATERIALS AND METHODS}

Instruments. The ${ }^{1} \mathrm{H}$ and ${ }^{13} \mathrm{C}$ NMR spectra were determined in $\mathrm{CDCl}_{3}$ solution using 400 and $100 \mathrm{MHz}$ spectrometers, respectively. The proton chemical shifts $(\delta)$ are relative to tetramethylsilane (TMS, $\delta=0.0$ ) as the internal standard and expressed in parts per million. Spin multiplicities are given as $\mathrm{s}$ (singlet), $\mathrm{d}$ (doublet), $\mathrm{t}$ (triplet), and $\mathrm{m}$ (multiplet) as well as brs (broad singlet). Coupling constants $(J)$ are listed in hertz. The infrared spectra were recorded by an Fourier transform infrared spectrometer. Melting points were determined using a Büchi melting point B-540 apparatus and are uncorrected. The MS spectra were obtained using a mass spectrometer. The HRMS was determined using a JEOL JNMAX 500 mass spectrometer.
Chemicals. All chemical reagents were commercially available. The solvents (chloroform (99\%), dimethyl sulfoxide (DMSO) (99\%), ethyl acetate (99\%), hexane (99\%), diethyl ether (99\%), tetrahydrofuran (THF) (99\%), and toluene (99\%)) were purchased from Tokyo Chemical Industry Co., Ltd. and were directly used without further purification. Unless otherwise stated, the reactions were monitored by thin layer chromatography on silica gel plates (60 F254) and visualized with ultraviolet light or iodine spray. Column chromatography was performed on silica gel (60-120 mesh) using hexane and ethyl acetate.

General Procedure for the Preparation of 3,4Dihydroquinoxalin-2 $(1 \mathrm{H})$-ones $1 \mathrm{a}-0$. A suspension of 2 bromoaniline (1 equiv), amino acid (2-3 equiv), copper chloride (I) (5-15 mol \%), potassium phosphate (2-3 equiv), and dimethylethylenediamine $(20-60 \mathrm{~mol} \%)$ in dry DMSO was degassed with $\mathrm{N}_{2}$ for $5 \mathrm{~min}$ and stirred at $110{ }^{\circ} \mathrm{C}$ under a nitrogen atmosphere for $24 \mathrm{~h}$. The reaction mixture was quenched with water and extracted with AcOEt. The organic layer was washed with water and a saturated aqueous solution of ammonium chloride and then dried over $\mathrm{Na}_{2} \mathrm{SO}_{4}$. After 
Table 2. Conversions of Quinoxalinones to 1,2,3,4-Tetrahydroquinoxalines and Their Olfactory Properties<smiles>[R]C1CNc2cc[nH+]cc2N([R3])C1C</smiles><smiles>Cc1cccc2c1NCCN2</smiles>

2a: $76 \%$

nutty, roasty, soy sauce, parched-barley flour, roasted soybean flour<smiles>Cc1ccc2c(c1)N[C@H](C)CN2</smiles>

2f: $93 \%$

phenolic, medicine, wet wood, feces<smiles>Cc1cc(C)c2c(c1)NCCN2</smiles>

2k: $82 \%$

roasted shrimp, fish meal, bouillabaisse, whole rice, benzaldehyde<smiles>Cc1ccc2c(c1)NCCN2</smiles>

2b: $93 \%$

roasty, cookie, cashew nut, chestnut, rice hull, fishy<smiles>Cc1ccc2c(c1)NC[C@@H](C)N2</smiles>

(S)-2g: $69 \%$

pyridine, medicine phenolic, plastic, woody, cooling,

Worcestershire sauce<smiles>C[C@H]1CNc2ccccc2N1</smiles>

2I: $78 \%$

chocolate, cacao, grilled fish, oolong tea, cherry<smiles>C[C@H]1CNc2ccccc2N1</smiles>

2c: $98 \%$

phenolic, pungent, squid, shrimp, lamb roast<smiles>Cc1cccc2c1N[C@H](C)CN2</smiles>

2h: $85 \%$

indole, skatole, leather, broad beans camphor<smiles>Cc1ccc2c(c1)N[C@H](C)CN2</smiles>

2m: $66 \%$

phenolic, medicine, paints<smiles>CCC1CNc2ccccc2N1</smiles>

2d: $97 \%$

medicine, smoky, nutty<smiles>CN1CCNc2ccccc21</smiles>

2i: $82 \%$

skatole, camphor, caramel<smiles>Cc1cccc2c1NC[C@@H](C)N2</smiles>

2n: $95 \%$

nutty, wafer, sesame, roasted soybean flour<smiles>Cc1cccc2c1NC[C@@H](C)N2</smiles>

2e: $91 \%$

roasty, barley tea, parched sesame, iodine, peanuts, roasted soybean flour<smiles>OCC1CNc2ccccc2N1</smiles>

2j: $79 \%$

phenolic, wood waste, leather, guaiacol<smiles>Cc1ccc2c(c1)NC[C@@H](C)N2</smiles>

(R)-20: $74 \%$

pyridine, pyrazine, plastic, medicine guaiacol, vanilla, woody, rush glass, tea leaf, black tea

Scheme 2. Synthesis of Quinoxalin-2 $(1 H)$-ones Starting from Quinoxalinones<smiles>Cc1cccc2c1NC(=O)CN2</smiles>

$$
\begin{aligned}
& \underset{\mathrm{PhMe}, \text { reflux, } 24 \mathrm{~h}}{\mathrm{~V}_{2} \mathrm{O}_{5} \text { (2.5 eq.) }} \\
& \underset{\mathrm{SiO}_{2}}{\mathrm{P} \%}
\end{aligned}
$$

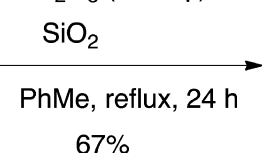

1a<smiles>CC1Nc2ccccc2NC1=O</smiles>

$1 c$

$$
\mathrm{V}_{2} \mathrm{O}_{5} \text { (2.5 eq.) }
$$

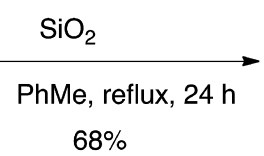

$68 \%$

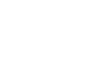<smiles>Cc1cccc2ncc(=O)[nH]c12</smiles>

$4 a$ filtration, the solvent was removed in vacuo. The residue was purified by silica gel column chromatography (eluent: hexanes/ $\mathrm{AcOEt}$ ) to afford the corresponding quinoxalin-2-one $\mathbf{1}$.

8-Methyl-3,4-dihydro-1H-quinoxalin-2-one (1a). 2-Bromo6-methylaniline (1.11 g, $6.00 \mathrm{mmol})$, glycine (0.90 g, 12.0 mmol), copper chloride (I) $(30 \mathrm{mg}, 0.3 \mathrm{mmol}), \mathrm{K}_{3} \mathrm{PO}_{4}(2.55 \mathrm{~g}$ $12.0 \mathrm{mmol})$, dimethylethylenediamine $(0.21 \mathrm{~g}, 2.4 \mathrm{mmol})$, and dry DMSO $(20 \mathrm{~mL})$ were used, and the reaction mixture was extracted with $\mathrm{CHCl}_{3}$ instead of AcOEt: pale brown solid; 550 $\mathrm{mg}, 56 \%$ yield; $R_{f}=0.36$ (hexanes $/$ AcOEt $=1 / 1$ ); mp 159.3$161.7{ }^{\circ} \mathrm{C}$; ${ }^{1} \mathrm{H}$ NMR $\left(400 \mathrm{MHz}, \mathrm{CDCl}_{3}\right) \delta 8.07$ (brs, $1 \mathrm{H}, \mathrm{NH}$ ), $6.81(\mathrm{t}, J=7.8 \mathrm{~Hz}, 1 \mathrm{H}, \mathrm{Ar}), 6.63(\mathrm{~d}, J=7.8 \mathrm{~Hz}, 1 \mathrm{H}, \mathrm{Ar}), 6.56$ (d, $J=7.8 \mathrm{~Hz}, 1 \mathrm{H}, \mathrm{Ar}$ ), 3.95 (d, $J=1.5 \mathrm{~Hz}, 2 \mathrm{H}), 3.87$ (brs, $1 \mathrm{H}$, $\mathrm{NH}), 2.24$ (s, 3H, Me); ${ }^{13} \mathrm{C} \mathrm{NMR}\left(100 \mathrm{MHz}, \mathrm{CDCl}_{3}\right) \delta 166.8$, 133.7, 123.9, 123.5, 123.3, 121.4, 112.1, 47.1, 16.5; IR (KBr) $\nu$ 3223, 2974, 1689, 1601, 1486, 1388, 1299, 796, $732 \mathrm{~cm}^{-1}$; HRMS (FAB) $m / z[\mathrm{M}+\mathrm{H}]^{+}$calcd for $\mathrm{C}_{9} \mathrm{H}_{11} \mathrm{ON}_{2}$ 163.0871, found 163.0876 .

6-Methyl-3,4-dihydro-1H-quinoxalin-2-one (1b). 2-Bromo4-methylaniline (1.49 g, $8.00 \mathrm{mmol})$, glycine (1.80 g, 24.0 $\mathrm{mmol}$ ), copper chloride (I) (45 mg, $0.4 \mathrm{mmol}), \mathrm{K}_{3} \mathrm{PO}_{4}(5.00 \mathrm{~g}$, $24.0 \mathrm{mmol})$, dimethylethylenediamine $(0.28 \mathrm{~g}, 3.2 \mathrm{mmol})$, and dry DMSO (25 mL) were used: yellow solid; $1.10 \mathrm{~g}$, $83 \%$ yield; $R_{f}=0.38$ (hexanes $/ \mathrm{AcOEt}=1 / 1$ ); $\mathrm{mp} 151.0-151.9{ }^{\circ} \mathrm{C} ;{ }^{1} \mathrm{H}$ NMR $\left(400 \mathrm{MHz}, \mathrm{CDCl}_{3}\right) \delta 9.20$ (brs, $\left.1 \mathrm{H}, \mathrm{NH}\right), 6.66(\mathrm{~d}, J=$ $8.0 \mathrm{~Hz}, 1 \mathrm{H}, \mathrm{Ar}$ ), 6.55 (d, J = 8.0 Hz, 1H, Ar), 6.49 (s, 1H, Ar), 
Table 3. Synthesis of Quinoxalines and Their Olfactory Properties<smiles></smiles><smiles>O=S(=O)(O)c1cccc2nccnc12</smiles>

nutty<smiles>Cc1ccc2nccnc2c1</smiles>

3b: $64 \%$<smiles>Cc1cnc2ccccc2n1</smiles>

3c: $55 \%$<smiles>CCc1cnc2ccccc2n1</smiles>

3d: $69 \%$<smiles>Cc1cnc2c(C)cccc2n1</smiles>

3e: $89 \%$ nutty, fenugleek, shrimp, coffee, soy sauce hazelnut, phenolic almond jelly<smiles>Cc1ccc2ncc(C)nc2c1</smiles>

3f: $79 \%$

phenolic, smoky, fatty, meat<smiles>Cc1cc(C)c2nccnc2c1</smiles>

3k: $80 \%$

pyrazine, thiazole, natty, smoky, medicine, wood chips<smiles>Cc1ccc2nc(C)cnc2c1</smiles>

3g: $77 \%$

plastic, rubber, medicine, pyridine, phenolic, sweet, black tea<smiles>Cc1cnc2cccc(C)c2n1</smiles>

3h: $77 \%$

pyrazine, smoky, nutty unpleasant fish, phenolic, cool<smiles>CN1CC=Nc2ccccc21</smiles>

3i: $0 \%$ pyrazine, earthy, roast chestnuts, crust, parched sesame, cooked meat solvent<smiles>O=Cc1cnc2ccccc2n1</smiles>

3j: $11 \%$

medicine, phenolic, cresol, indole, wood waste, dried bonito

$3.96(\mathrm{~d}, J=1.2 \mathrm{~Hz}, 2 \mathrm{H}), 3.81$ (brs, $1 \mathrm{H}, \mathrm{NH}), 2.23$ (s, 3H, Me);

${ }^{13} \mathrm{C}$ NMR $\left(100 \mathrm{MHz}, \mathrm{CDCl}_{3}\right) \delta 167.2,133.7,133.5,123.1$, 120.1, 115.6, 114.6, 47.1, 20.9; IR (KBr) $\nu ~ 3368,3067,1682$, 1523, 1408, 1299, $804 \mathrm{~cm}^{-1}$; HRMS (FAB) $m / z[\mathrm{M}+\mathrm{H}]^{+}$ calcd for $\mathrm{C}_{9} \mathrm{H}_{11} \mathrm{ON}_{2}$ 163.0872, found 163.0858 .

(S)-3-Methyl-3,4-dihydro-1 H-quinoxalin-2-one (1c). ${ }^{10} 2$ Bromoaniline $(688 \mathrm{mg}, 4.00 \mathrm{mmol})$, L-alanine $(713 \mathrm{mg}, 8.00$ $\mathrm{mmol})$, copper chloride (I) $(20 \mathrm{mg}, 0.2 \mathrm{mmol}), \mathrm{K}_{3} \mathrm{PO}_{4}(1.75 \mathrm{~g}$, $8.00 \mathrm{mmol})$, dimethylethylenediamine $(140 \mathrm{mg}, 1.6 \mathrm{mmol})$, and dry DMSO $(10 \mathrm{~mL})$ were used: white solid; $562 \mathrm{mg}, 87 \%$ yield; $R_{f}=0.39$ (hexanes $/$ AcOEt $=1 / 1$ ); mp $116.2-118.5{ }^{\circ} \mathrm{C}$ (lit. $\left.112.4{ }^{\circ} \mathrm{C}\right) ;^{10}[\alpha]_{\mathrm{D}}^{22}=+54.20\left(c 0.20, \mathrm{CHCl}_{3}\right)\left(\right.$ lit. $[\alpha]_{\mathrm{D}}^{22}=$ $\left.+8.30\left(c 0.60, \mathrm{CHCl}_{3}\right)\right) ;{ }^{10}{ }^{1} \mathrm{H}$ NMR $\left(400 \mathrm{MHz}, \mathrm{CDCl}_{3}\right) \delta 8.59$ (brs, $1 \mathrm{H}, \mathrm{NH}$ ), 6.89 (dt, $J=8.0,2.8 \mathrm{~Hz}, 1 \mathrm{H}, \mathrm{Ar}$ ), 6.80-6.73 (m, 2H, Ar), $6.68(\mathrm{~d}, J=8.0 \mathrm{~Hz}, 1 \mathrm{H}, \mathrm{Ar}), 4.02(\mathrm{q}, J=6.6 \mathrm{~Hz}$, $1 \mathrm{H}), 3.85$ (brs, $1 \mathrm{H}, \mathrm{NH}), 1.46(\mathrm{~d}, J=6.6 \mathrm{~Hz}, 3 \mathrm{H}, \mathrm{Me}) ;{ }^{13} \mathrm{C}$ NMR $\left(100 \mathrm{MHz}, \mathrm{CDCl}_{3}\right) \delta 169.8,133.4,125.6,123.7,119.5$, $115.5,114.0,51.8,17.9$.

dl-3-Ethyl-3,4-dihydro-1H-quinoxalin-2-one (1d). ${ }^{11}$ 2-Bromoaniline (1.37 g, $8.00 \mathrm{mmol})$, a-aminobutynic acid (2.36 g, $24.0 \mathrm{mmol})$, copper chloride (I) $(40 \mathrm{mg}, 0.4 \mathrm{mmol}), \mathrm{K}_{3} \mathrm{PO}_{4}$ (5.02 g, $24.0 \mathrm{mmol})$, dimethylethylenediamine $(280 \mathrm{mg}, 3.2$ $\mathrm{mmol})$, and dry DMSO (25 mL) were used: yellow solid; 1.38 g, 98\% yield; $R_{f}=0.24$ (hexanes $\left./ \mathrm{AcOEt}=2 / 1\right)$; mp 85.8-87.4 ${ }^{\circ} \mathrm{C}$ (lit. 77.4-78.5 $\left.{ }^{\circ} \mathrm{C}\right) ;{ }^{11}{ }^{1} \mathrm{H} \mathrm{NMR}\left(400 \mathrm{MHz}, \mathrm{CDCl}_{3}\right) \delta 9.30$ (brs, 1H, NH), $6.88(\mathrm{dt}, J=7.6,1.6 \mathrm{~Hz}, 1 \mathrm{H}, \mathrm{Ar}), 6.79-6.71$ (m, 2H, Ar), 6.67 (d, J = 7.6 Hz, 1H, Ar), 3.99 (brs, $1 \mathrm{H}, \mathrm{NH}$ ), 3.87 (ddd, $J=8.4,5.2,1.2 \mathrm{~Hz}, 1 \mathrm{H}), 1.93-1.74\left(\mathrm{~m}, 2 \mathrm{H}, \mathrm{CH}_{2}\right)$, $1.03(\mathrm{t}, J=7.6 \mathrm{~Hz}, 3 \mathrm{H}, \mathrm{Me}) ;{ }^{13} \mathrm{C} \mathrm{NMR}\left(100 \mathrm{MHz}, \mathrm{CDCl}_{3}\right) \delta$ 169.1, 133.0, 125.2, 123.8, 119.2, 115.3, 114.0, 57.5, 25.1, 9.6.

(S)-3,8-Dimethyl-3,4-dihydro-1H-quinoxalin-2-one (1e). ${ }^{12}$ 2-Bromo-6-methylaniline (186 mg, $1.00 \mathrm{mmol})$, L-alanine (180 mg, $2.00 \mathrm{mmol}$ ), copper chloride (I) (5 mg, 0.05 $\mathrm{mmol}), \mathrm{K}_{3} \mathrm{PO}_{4}(405 \mathrm{mg}, 2.00 \mathrm{mmol}$ ), dimethylethylenediamine (35 mg, $0.4 \mathrm{mmol})$, and dry DMSO $(5 \mathrm{~mL})$ were used: pale brown solid; $125 \mathrm{mg}, 71 \%$ yield; $R_{f}=0.38$ (hexanes $/ \mathrm{AcOEt}=$ 3/2); mp 104.1-105.4 ${ }^{\circ} \mathrm{C} ;[\alpha]_{\mathrm{D}}^{23}=+61.37\left(\right.$ c 0.18, $\left.\mathrm{CHCl}_{3}\right) ;{ }^{1} \mathrm{H}$ NMR (400 MHz, $\left.\mathrm{CDCl}_{3}\right) \delta 8.12($ brs, $1 \mathrm{H}, \mathrm{NH}), 6.80$ (dd, $J=$ $7.8,7.6 \mathrm{~Hz}, 1 \mathrm{H}, \mathrm{Ar}), 6.63(\mathrm{~d}, J=7.6 \mathrm{~Hz}, 1 \mathrm{H}, \mathrm{Ar}), 6.56$ (d, $J=$ $7.8 \mathrm{~Hz}, 1 \mathrm{H}, \mathrm{Ar}$ ), 3.97 (q, $J=6.6 \mathrm{~Hz}, 1 \mathrm{H}), 3.86$ (brs, $1 \mathrm{H}, \mathrm{NH}$ ), $2.24(\mathrm{~s}, 3 \mathrm{H}, \mathrm{Me}), 1.45$ (d, $J=6.6 \mathrm{~Hz}, 3 \mathrm{H}, \mathrm{Me}) ;{ }^{13} \mathrm{C} \mathrm{NMR}(100$ $\left.\mathrm{MHz}, \mathrm{CDCl}_{3}\right) \delta 169.3,133.5,124.0,123.4,123.2,121.4,112.2$, 51.6, 17.4, 16.5.

(S)-3,6-Dimethyl-3,4-dihydro-1H-quinoxalin-2-one (1f). ${ }^{13}$ 2-Bromo-4-methylaniline (1.48 g, $8.00 \mathrm{mmol})$, L-alanine $(1.42$ g, $16.0 \mathrm{mmol}$ ), copper chloride (I) $(40 \mathrm{mg}, 0.4 \mathrm{mmol}), \mathrm{K}_{3} \mathrm{PO}_{4}$ (3.41 g, $16.0 \mathrm{mmol})$, dimethylethylenediamine $(0.28 \mathrm{~g}, 3.2$ $\mathrm{mmol})$, and dry DMSO $(20 \mathrm{~mL})$ were used: pale yellow solid; $1.13 \mathrm{~g}, 81 \%$ yield; $R_{f}=0.55$ (hexanes $/$ AcOEt $=1 / 1$ ); mp 128.5-131.7 ${ }^{\circ} \mathrm{C}$; $[\alpha]_{\mathrm{D}}^{22}=+48.76\left(\right.$ c $\left.0.18, \mathrm{CHCl}_{3}\right) ;{ }^{1} \mathrm{H}$ NMR 


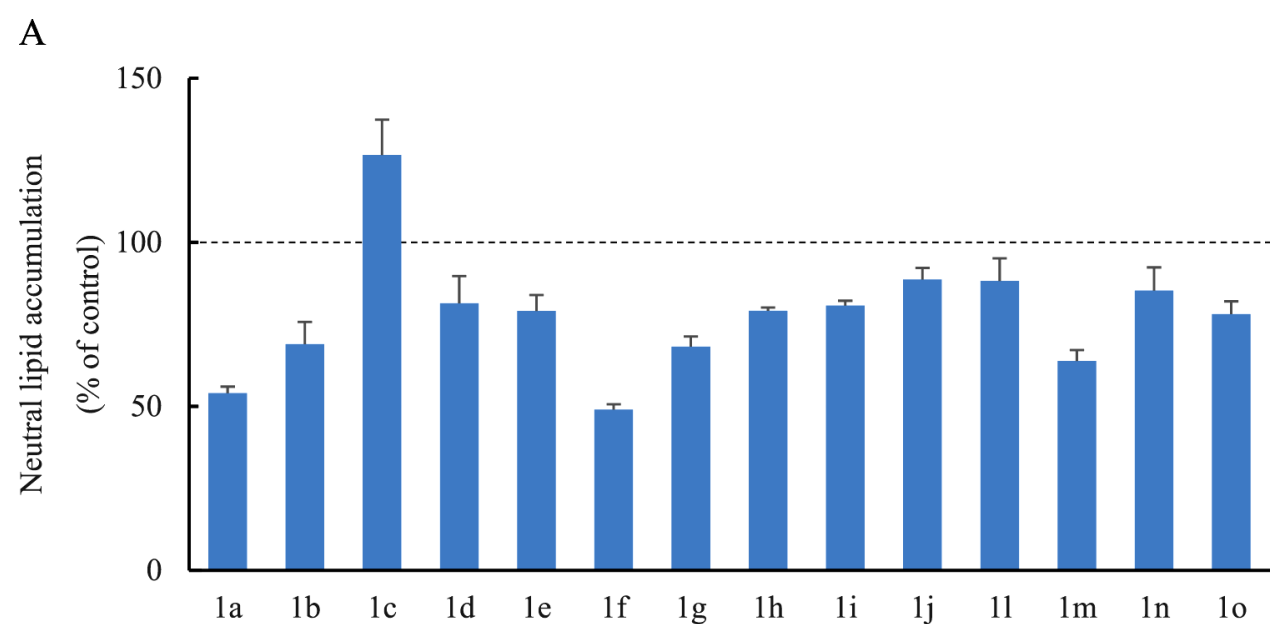

B

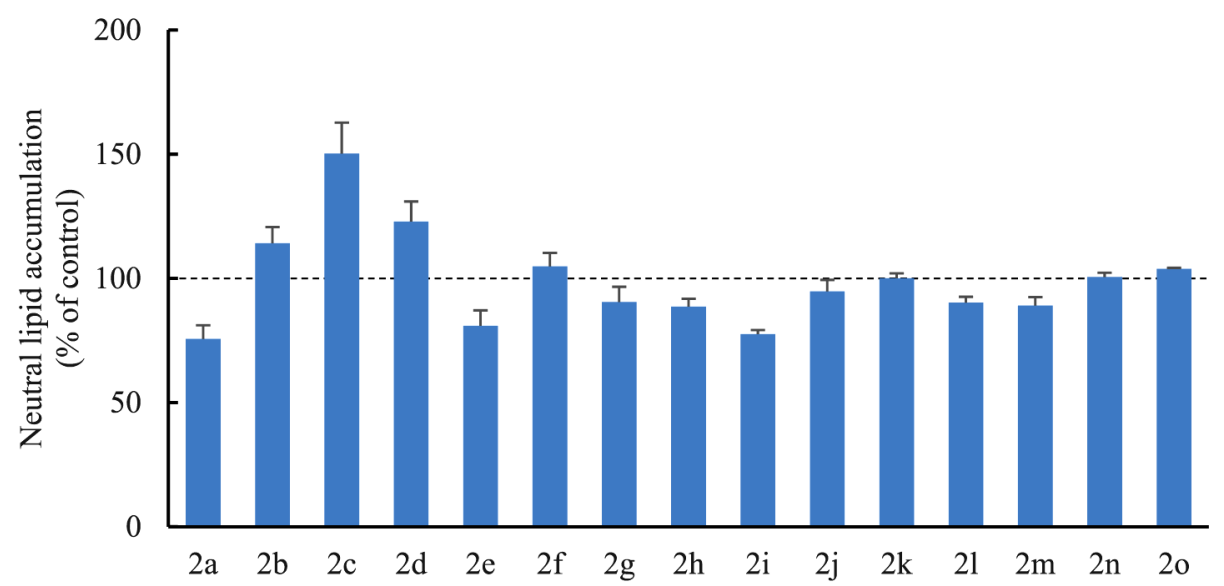

$\mathrm{C}$

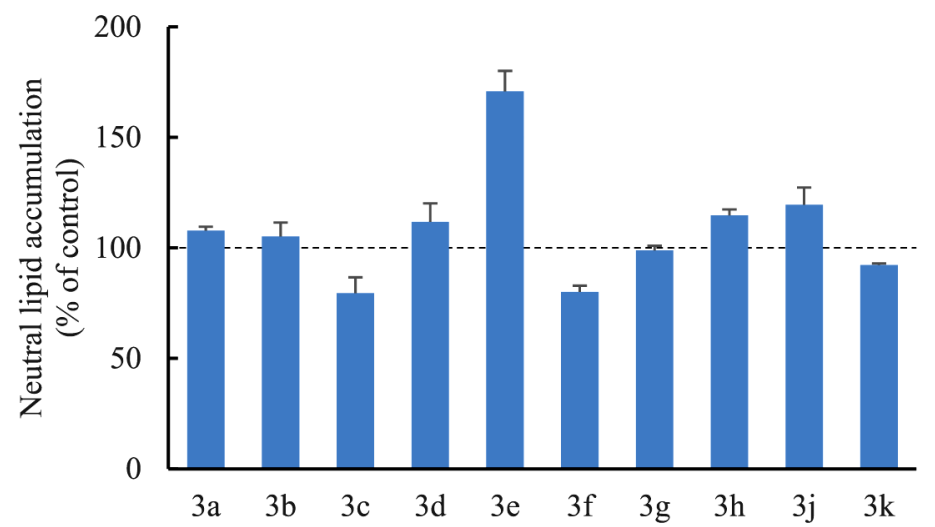

Figure 2. Effects of quinoxaline derivatives on palmitate-induced lipid accumulation in HepG2 cells. The cells were incubated with each quinoxaline derivative $(10 \mu \mathrm{M})$ in the presence of $0.5 \mathrm{mM}$ palmitate for $24 \mathrm{~h}$ in serum-free Dulbecco's modified Eagle's medium (DMEM). The neutral lipid level normalized to the cellular protein content was determined by Oil Red O staining. (A) Quinoxalinones 1a-o. (B) Tetrahydroquinoxalines 2ao. (C) Quinoxalines $3 a-k$. Compounds $1 \mathbf{k}$, $4 \mathbf{a}$, and $4 \mathbf{c}$ could not be dissolved in media, so they were not included in the data.

$\left(400 \mathrm{MHz}, \mathrm{CDCl}_{3}\right) \delta 8.92(\mathrm{brs}, 1 \mathrm{H}, \mathrm{NH}), 6.66(\mathrm{~d}, J=7.8 \mathrm{~Hz}$, $1 \mathrm{H}, \mathrm{Ar}), 6.56(\mathrm{~d}, J=7.8 \mathrm{~Hz}, 1 \mathrm{H}, \mathrm{Ar}), 6.50(\mathrm{~s}, 1 \mathrm{H}, \mathrm{Ar}), 3.99(\mathrm{q}$, $J=6.6 \mathrm{~Hz}, 1 \mathrm{H}), 3.79(\mathrm{brs}, 1 \mathrm{H}, \mathrm{NH}), 2.24(\mathrm{~s}, 3 \mathrm{H}, \mathrm{Me}), 1.44(\mathrm{~d}$, $J=6.6 \mathrm{~Hz}, 3 \mathrm{H}, \mathrm{Me}) ;{ }^{13} \mathrm{C} \mathrm{NMR}\left(100 \mathrm{MHz}, \mathrm{CDCl}_{3}\right) \delta 169.5$, 133.5, 133.2, 123.2, 120.1, 115.3, 114.7, 51.9, 20.9, 17.9.

(S)-3,7-Dimethyl-3,4-dihydro-1H-quinoxalin-2-one (1g). 2 Bromo-5-methylaniline $(558 \mathrm{mg}, 3.00 \mathrm{mmol})$, L-alanine (534 $\mathrm{mg}, 6.00 \mathrm{mmol})$, copper chloride (I) $(15 \mathrm{mg}, 0.15 \mathrm{mmol})$, $\mathrm{K}_{3} \mathrm{PO}_{4}(1.27 \mathrm{~g}, 6.00 \mathrm{mmol})$, dimethylethylenediamine (106 mg, $1.20 \mathrm{mmol})$, and dry DMSO $(10 \mathrm{~mL})$ were used: pale yellow solid; $408 \mathrm{mg}$, 77\% yield; $R_{f}=0.38$ (hexanes $\left./ \mathrm{AcOEt}=1 / 1\right)$; mp 161.7-164.0 ${ }^{\circ} \mathrm{C} ;[\alpha]_{\mathrm{D}}^{22}=+48.69\left(c 0.16, \mathrm{CHCl}_{3}\right) ;{ }^{1} \mathrm{H}$ NMR $\left(400 \mathrm{MHz}, \mathrm{CDCl}_{3}\right) \delta 8.93(\mathrm{brs}, 1 \mathrm{H}, \mathrm{NH}), 6.70(\mathrm{~d}, J=8.0 \mathrm{~Hz}$, $1 \mathrm{H}, \mathrm{Ar}), 6.59$ (d, $J=8.0 \mathrm{~Hz}, 2 \mathrm{H}, \mathrm{Ar}), 3.99(\mathrm{q}, J=6.6 \mathrm{~Hz}, 1 \mathrm{H})$, 
3.75 (brs, $1 \mathrm{H}, \mathrm{NH}$ ), 2.25 (s, 3H, Me), 1.45 (d, $J=6.8 \mathrm{~Hz}, 3 \mathrm{H}$, $\mathrm{Me}) ;{ }^{13} \mathrm{C} \mathrm{NMR}\left(100 \mathrm{MHz}, \mathrm{CDCl}_{3}\right) \delta 170.0,131.0,129.3$,

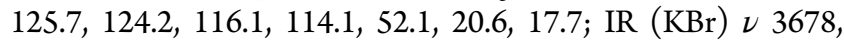
2958, 1660, 1621, 1562, 1397, 1193, 886, $822 \mathrm{~cm}^{-1}$; HRMS (FAB) $m / z[\mathrm{M}+\mathrm{H}]^{+}$calcd for $\mathrm{C}_{10} \mathrm{H}_{13} \mathrm{ON}_{2}$ 177.1028, found 177.1031 .

(S)-3,5-Dimethyl-3,4-dihydro-1H-quinoxalin-2-one (1h). ${ }^{12}$ 2-Bromo-3-methylaniline ( $97 \mathrm{mg}, 0.5 \mathrm{mmol})$, L-alanine $(90 \mathrm{mg}$, $1.0 \mathrm{mmol})$, copper chloride (I) $(7.8 \mathrm{mg}, 0.07 \mathrm{mmol}), \mathrm{K}_{3} \mathrm{PO}_{4}$ $(212 \mathrm{mg}, 1.00 \mathrm{mmol})$, dimethylethylenediamine $(26 \mathrm{mg}, 0.3$ $\mathrm{mmol})$, and dry DMSO $(2.5 \mathrm{~mL})$ were used, and the reaction mixture was stirred for $48 \mathrm{~h}$ : dark yellow solid; $56 \mathrm{mg}, 61 \%$ yield; $R_{f}=0.34$ (hexanes $\left./ \mathrm{AcOEt}=3 / 2\right)$; $\mathrm{mp} 124.5-125.3{ }^{\circ} \mathrm{C}$; $[\alpha]_{\mathrm{D}}^{23}=+5.55\left(c 0.18, \mathrm{CHCl}_{3}\right) ;{ }^{1} \mathrm{H} \mathrm{NMR}\left(400 \mathrm{MHz}, \mathrm{CDCl}_{3}\right) \delta$ 8.80 (brs, $1 \mathrm{H}, \mathrm{NH}), 6.78(\mathrm{dq}, J=6.1,1.0 \mathrm{~Hz}, 1 \mathrm{H}, \mathrm{Ar}), 6.69$ (dd, $J=7.8,1.7 \mathrm{~Hz}, 1 \mathrm{H}, \mathrm{Ar}), 6.65$ (dd, $J=7.8,1.7 \mathrm{~Hz}, 1 \mathrm{H}, \mathrm{Ar}), 4.05$ (dq, $J=6.5,2.0 \mathrm{~Hz}, 1 \mathrm{H}), 3.72$ (brs, $1 \mathrm{H}, \mathrm{NH}), 2.18$ (s, 3H, Me), $1.48(\mathrm{~d}, J=6.8 \mathrm{~Hz}, 3 \mathrm{H}, \mathrm{Me}) ;{ }^{13} \mathrm{C} \mathrm{NMR}\left(100 \mathrm{MHz}, \mathrm{CDCl}_{3}\right) \delta$ $169.4,131.5,125.2,125.1,121.9,118.9,113.5,51.8,18.1,16.6$.

4-Methyl-3,4-dihydro-1H-quinoxalin-2-one (1i). ${ }^{14}$ 2-Bromoaniline $(1.03 \mathrm{~g}, 6.0 \mathrm{mmol})$, sarcosine $(1.07 \mathrm{~g}, 12.0 \mathrm{mmol})$, copper chloride (I) $(59 \mathrm{mg}, 0.6 \mathrm{mmol}), \mathrm{K}_{3} \mathrm{PO}_{4}(2.55 \mathrm{~g}, 12$ mmol), dimethylethylenediamine (212 $\mathrm{mg}, 2.4 \mathrm{mmol})$, and dry DMSO (14 mL) were used: gray solid; $644 \mathrm{mg}, 66 \%$ yield; $R_{f}=$ 0.35 (hexanes/AcOEt $=3 / 2$ ); $\mathrm{mp} 144.0-146.7{ }^{\circ} \mathrm{C}$ (lit. $140-$ $\left.143^{\circ} \mathrm{C}\right) ;{ }^{14}{ }^{1} \mathrm{H}$ NMR $\left(400 \mathrm{MHz}, \mathrm{CDCl}_{3}\right) \delta 9.41$ (brs, $1 \mathrm{H}, \mathrm{NH}$ ), $6.99(\mathrm{dt}, J=8.1,2.0 \mathrm{~Hz}, 1 \mathrm{H}, \mathrm{Ar}), 6.83-6.70(\mathrm{~m}, 2 \mathrm{H}, \mathrm{Ar}), 6.67$ (d, $J=8.1 \mathrm{~Hz}, 1 \mathrm{H}, \mathrm{Ar}), 3.78(\mathrm{~s}, 2 \mathrm{H}), 2.85(\mathrm{~s}, 3 \mathrm{H}, \mathrm{Me}) ;{ }^{13} \mathrm{C}$ NMR $\left(100 \mathrm{MHz}, \mathrm{CDCl}_{3}\right) \delta 167.6,136.1,126.3,124.2,119.1$, 115.4, 111.5, 54.7, 37.3.

(S)-3-Hydroxymethyl-3,4-dihydro-1H-quinoxalin-2-one (1j). ${ }^{10}$ 2-Bromoaniline (4.3 g, $\left.25 \mathrm{mmol}\right)$, L-serin (7.9 g, 75 $\mathrm{mmol})$, copper chloride (I) $(248 \mathrm{mg}, 2.5 \mathrm{mmol}), \mathrm{K}_{3} \mathrm{PO}_{4}(16 \mathrm{~g}$, $75 \mathrm{mmol})$, dimethylethylenediamine $(1.7 \mathrm{~g}, 20 \mathrm{mmol})$, and dry DMSO $(60 \mathrm{~mL})$ were used, and the reaction mixture was stirred for $70 \mathrm{~h}$ : pale brown solid; $2.16 \mathrm{~g}$, $48 \%$ yield; $R_{f}=0.33$ (hexanes/AcOEt = 1/4); mp 128.7-134.0 ${ }^{\circ} \mathrm{C}\left(\right.$ lit. $\left.80.3{ }^{\circ} \mathrm{C}\right){ }^{7}$ $[\alpha]_{\mathrm{D}}^{22}=+17.44\left(c 0.18, \mathrm{CHCl}_{3}\right)\left(\right.$ lit. $[\alpha]_{\mathrm{D}}^{22}=+19.6$ (c 0.3 , $\left.\left.\mathrm{CHCl}_{3}\right)\right) ;{ }^{10}{ }^{1} \mathrm{H}$ NMR $\left(400 \mathrm{MHz}, \mathrm{CDCl}_{3}\right) \delta 8.13$ (brs, $1 \mathrm{H}$, $\mathrm{NH}), 6.92(\mathrm{dt}, J=7.6,1.2 \mathrm{~Hz}, 1 \mathrm{H}, \mathrm{Ar}), 6.77(\mathrm{dt}, J=7.6,1.2 \mathrm{~Hz}$, $1 \mathrm{H}, \mathrm{Ar}), 6.72(\mathrm{dd}, J=7.6,1.2 \mathrm{~Hz}, 2 \mathrm{H}, \mathrm{Ar}), 4.16$ (brs, $1 \mathrm{H}, \mathrm{NH}$ ), $4.11(\mathrm{t}, J=6.0 \mathrm{~Hz}, 1 \mathrm{H}), 4.06(\mathrm{dd}, J=10.8,6.0 \mathrm{~Hz}, 1 \mathrm{H}), 3.90$ $(\mathrm{dd}, J=10.8,6.0 \mathrm{~Hz}, 1 \mathrm{H}), 2.63(\mathrm{~s}, 1 \mathrm{H}, \mathrm{OH}) ;{ }^{13} \mathrm{C} \mathrm{NMR}(100$ $\left.\mathrm{MHz}, \mathrm{CDCl}_{3}\right) \delta 162.1,133.0,124.7,124.2,119.7,115.4,114.3$, 63.0, 57.0.

6,8-Dimethyl-1H-quinoxalin-2-one (1k). 2-Bromo-4,6-dimethylaniline $(1.6 \mathrm{~g}, 8.0 \mathrm{mmol})$, glycine $(1.2 \mathrm{~g}, 16.0 \mathrm{mmol})$, copper chloride (I) $(40 \mathrm{mg}, 0.4 \mathrm{mmol}), \mathrm{K}_{3} \mathrm{PO}_{4}(3.4 \mathrm{~g}, 16$ $\mathrm{mmol})$, dimethylethylenediamine $(0.28 \mathrm{~g}, 3.2 \mathrm{mmol})$, and dry DMSO (20 mL) were used: yellow solid; $883 \mathrm{mg}, 63 \%$ yield; $R_{f}$ $=0.36$ (hexanes $/ \mathrm{AcOEt}=1 / 1) ; \mathrm{mp} 215.2-217.9{ }^{\circ} \mathrm{C} ;{ }^{1} \mathrm{H}$ NMR $\left(400 \mathrm{MHz}, \mathrm{CDCl}_{3}\right) \delta 11.42$ (brs, $\left.1 \mathrm{H}, \mathrm{NH}\right), 8.31$ (s, $\left.1 \mathrm{H}\right), 7.51$ (s, 1H, Ar), 7.23 (s, 1H, Ar), $2.55(\mathrm{~s}, 3 \mathrm{H}, \mathrm{Me}), 2.42(\mathrm{~s}, 3 \mathrm{H}$, $\mathrm{Me}) ;{ }^{13} \mathrm{C}$ NMR $\left(100 \mathrm{MHz}, \mathrm{CDCl}_{3}\right) \delta 156.5,150.1,133.7$,

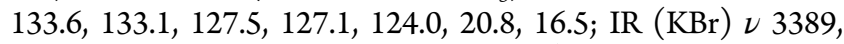
3158, 3032, 1669, 1560, 1473, $861 \mathrm{~cm}^{-1}$; HRMS (FAB) $\mathrm{m} / z$ $[\mathrm{M}+\mathrm{H}]^{+}$calcd for $\mathrm{C}_{10} \mathrm{H}_{11} \mathrm{ON}_{2}$ 175.0871, found 175.0862 .

(R)-3-Methyl-3,4-dihydro-1H-quinoxalin-2-one (1I). ${ }^{10}$ 2Bromoaniline $(688 \mathrm{mg}, 4.00 \mathrm{mmol})$, D-alanine $(715 \mathrm{mg}, 8.00$ mmol), copper chloride (I) $(20 \mathrm{mg}, 0.2 \mathrm{mmol}), \mathrm{K}_{3} \mathrm{PO}_{4}(1.75 \mathrm{~g}$, $8.00 \mathrm{mmol})$, dimethylethylenediamine $(70 \mathrm{mg}, 0.8 \mathrm{mmol})$, and dry DMSO (15 mL) were used: pale yellow solid; $564 \mathrm{mg}, 87 \%$ yield; $R_{f}=0.31$ (hexanes $/ \mathrm{AcOEt}=1 / 1$ ); $\mathrm{mp} 116.4-117.3{ }^{\circ} \mathrm{C}$ (lit. $\left.112.4{ }^{\circ} \mathrm{C}\right) ;{ }^{10}[\alpha]_{\mathrm{D}}^{23}=-62.19\left(c 0.19, \mathrm{CHCl}_{3}\right) ;{ }^{1} \mathrm{H}$ NMR $\left(400 \mathrm{MHz} \mathrm{CDCl}_{3}\right) \delta 9.23$ (brs, $\left.1 \mathrm{H}, \mathrm{NH}\right), 6.88(\mathrm{dt}, J=7.8,1.8$ $\mathrm{Hz}, 1 \mathrm{H}, \mathrm{Ar}), 6.82-6.71(\mathrm{~m}, 2 \mathrm{H}, \mathrm{Ar}), 6.68$ (d, $J=7.8 \mathrm{~Hz}, 1 \mathrm{H})$, 4.02 (q, $J=6.8 \mathrm{~Hz}, 1 \mathrm{H}), 3.89$ (brs, $1 \mathrm{H}, \mathrm{NH}), 1.46$ (d, $J=6.8$ $\mathrm{Hz}, 3 \mathrm{H}, \mathrm{Me}) ;{ }^{13} \mathrm{C} \mathrm{NMR}\left(100 \mathrm{MHz}, \mathrm{CDCl}_{3}\right) \delta 169.8,133.4$, $125.6,123.7,119.5,115.5,114.0,51.8,17.9$.

(R)-3,6-Dimethyl-3,4-dihydro-1H-quinoxalin-2-one $(1 \mathrm{~m}) .^{13}$ 2-Bromo-4-methylaniline (744 mg, $4.00 \mathrm{mmol})$, D-alanine (713 $\mathrm{mg}, 8.00 \mathrm{mmol})$, copper chloride (I) $(20 \mathrm{mg}, 0.2 \mathrm{mmol})$, $\mathrm{K}_{3} \mathrm{PO}_{4}(1.70 \mathrm{~g}, 8.00 \mathrm{mmol})$, dimethylethylenediamine $(0.14 \mathrm{~g}$, $1.6 \mathrm{mmol})$, and dry DMSO $(15 \mathrm{~mL})$ were used: pale orange solid; $604 \mathrm{mg}, 86 \%$ yield; $R_{f}=0.41$ (hexanes $/$ AcOEt $=1 / 1$ ); $\mathrm{mp} 125.7-127.5{ }^{\circ} \mathrm{C} ;[\alpha]_{\mathrm{D}}^{22}=-64.70\left(\right.$ c $\left.0.18, \mathrm{CHCl}_{3}\right) ;{ }^{1} \mathrm{H}$ NMR $\left(400 \mathrm{MHz}, \mathrm{CDCl}_{3}\right) \delta 9.12($ brs, $1 \mathrm{H}, \mathrm{NH}), 6.67$ (d, $J=$ $7.6 \mathrm{~Hz}, 1 \mathrm{H}, \mathrm{Ar}), 6.56$ (d, J = 7.6 Hz, 1H, Ar), 6.49 (s, $1 \mathrm{H}, \mathrm{Ar}$ ), $4.00(\mathrm{q}, J=6.4 \mathrm{~Hz}, 1 \mathrm{H}), 3.80$ (brs, $1 \mathrm{H}, \mathrm{NH}), 2.24$ (s, 3H, Me), $1.44(\mathrm{~d}, J=6.4 \mathrm{~Hz}, 3 \mathrm{H}, \mathrm{Me}) ;{ }^{13} \mathrm{C} \mathrm{NMR}\left(100 \mathrm{MHz}, \mathrm{CDCl}_{3}\right) \delta$ $169.6,133.5,133.2$, 123.2, 120.1, 115.3, 114.7, 51.9, 20.9, 17.9.

(R)-3,8-Dimethyl-3,4-dihydro-1H-quinoxalin-2-one (1n). ${ }^{12}$ 2-Bromo-6-methylaniline $(746 \mathrm{mg}, 4.00 \mathrm{mmol})$, D-alanine $(713$ $\mathrm{mg}, 8.00 \mathrm{mmol})$, copper chloride (I) $(20 \mathrm{mg}, 0.2 \mathrm{mmol})$, $\mathrm{K}_{3} \mathrm{PO}_{4}(1.7 \mathrm{~g}$, $8.0 \mathrm{mmol})$, dimethylethylenediamine $(141 \mathrm{mg}$, $1.60 \mathrm{mmol})$, and dry DMSO $(15 \mathrm{~mL})$ were used: pale orange solid; $493 \mathrm{mg}, 70 \%$ yield; $R_{f}=0.42$ (hexanes $/$ AcOEt $\left.=1 / 1\right)$; mp 93.7-95.2 ${ }^{\circ} \mathrm{C}$; $[\alpha]_{\mathrm{D}}^{21}=-65.39\left(c \mathrm{0.16}, \mathrm{CHCl}_{3}\right) ;{ }^{1} \mathrm{H} \mathrm{NMR}$ $\left(400 \mathrm{MHz}, \mathrm{CDCl}_{3}\right) \delta 8.07$ (brs, $\left.1 \mathrm{H}, \mathrm{NH}\right), 6.81(\mathrm{t}, J=7.8 \mathrm{~Hz}$, $1 \mathrm{H}, \mathrm{Ar}), 6.64(\mathrm{~d}, J=7.8 \mathrm{~Hz}, 1 \mathrm{H}, \mathrm{Ar}), 6.56(\mathrm{~d}, J=7.8 \mathrm{~Hz}, 1 \mathrm{H}$, Ar), 3.97 (q, $J=6.1 \mathrm{~Hz}, 1 \mathrm{H}), 3.85$ (brs, $1 \mathrm{H}, \mathrm{NH}), 2.24(\mathrm{~s}, 3 \mathrm{H}$, $\mathrm{Me}), 1.45(\mathrm{~d}, J=6.6 \mathrm{~Hz}, 3 \mathrm{H}, \mathrm{Me}) ;{ }^{13} \mathrm{C} \mathrm{NMR}(100 \mathrm{MHz}$, $\left.\mathrm{CDCl}_{3}\right) \delta 169.2,133.5,124.1,123.2,1232,121.4,112.2,51.7$, $17.5,16.5$.

(R)-3,7-Dimethyl-3,4-dihydro-1H-quinoxalin-2-one (1o). 2Bromo-5-methylaniline (372 mg, $2.00 \mathrm{mmol})$, D-alanine (358 $\mathrm{mg}, 4.00 \mathrm{mmol})$, copper chloride (I) (11 mg, $0.1 \mathrm{mmol})$, $\mathrm{K}_{3} \mathrm{PO}_{4}(849 \mathrm{mg}, 4.00 \mathrm{mmol})$, dimethylethylenediamine (70 $\mathrm{mg}, 0.8 \mathrm{mmol})$, and dry DMSO $(7 \mathrm{~mL})$ were used: pale brown solid; $253 \mathrm{mg}$, $72 \%$ yield; $R_{f}=0.31$ (hexanes $/$ AcOEt $=1 / 1$ ); mp 156.0-159.1 ${ }^{\circ} \mathrm{C} ;[\alpha]_{\mathrm{D}}^{22}=-47.03\left(c \quad 0.15, \mathrm{CHCl}_{3}\right) ;{ }^{1} \mathrm{H}$ NMR $\left(400 \mathrm{MHz}, \mathrm{CDCl}_{3}\right) \delta 8.98($ brs, $1 \mathrm{H}, \mathrm{NH}), 6.69$ (d, $J=$ $7.8 \mathrm{~Hz}, 1 \mathrm{H}, \mathrm{Ar}$ ), 6.59 (d, $J=7.8 \mathrm{~Hz}, 2 \mathrm{H}, \mathrm{Ar}), 3.98$ (q, $J=6.8$ $\mathrm{Hz}, 1 \mathrm{H}), 3.75$ (brs, 1H, NH), 2.24 (s, 3H, Me), 1.45 (d, $J=6.6$ $\mathrm{Hz}, \mathrm{Me}) ;{ }^{13} \mathrm{C}$ NMR $\left(100 \mathrm{MHz}, \mathrm{CDCl}_{3}\right) \delta 170.0,130.9,129.3$,

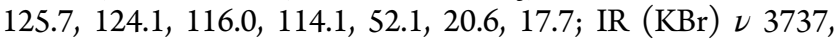
2951, 1660, 1620, 1561, 1396, 1193, 886, $822 \mathrm{~cm}^{-1}$; HRMS (FAB) $m / z[\mathrm{M}+\mathrm{H}]^{+}$calcd for $\mathrm{C}_{10} \mathrm{H}_{13} \mathrm{ON}_{2}$ 177.1028, found 177.1019 .

General Procedure for Synthesis of 1,2,3,4-Tetrahydroquinoxalines. Lithium aluminum hydride (6.5-8.8 equiv) was dissolved in dry THF under nitrogen at $0{ }^{\circ} \mathrm{C}$. To the stirred solution, over a period of $5 \mathrm{~min}$, was added a solution of quinoxalin-2-one in dry $\mathrm{THF}$ at $0{ }^{\circ} \mathrm{C}$, and the mixture was refluxed for $18 \mathrm{~h}$. The resulting reaction mixture was quenched with water and AcOEt and filtered through a Celite plug; then the solution was dried over $\mathrm{Na}_{2} \mathrm{SO}_{4}$. After filtration, the solvent was removed in vacuo. The residue was purified by silica gel column chromatography (eluent: hexanes/AcOEt) to afford the corresponding 1,2,3,4-tetrahydroquinoxaline 2 .

5-Methyl-1,2,3,4-tetrahydroquinoxaline (2a). ${ }^{15}$ 8-Methyl3,4-dihydro-1H-quinoxalin-2-one $1 \mathrm{a}(100 \mathrm{mg}, 0.60 \mathrm{mmol})$, lithium aluminum hydride $(152 \mathrm{mg}, 4.00 \mathrm{mmol})$, and dry THF $(10 \mathrm{~mL})$ were used: brown liquid; $69 \mathrm{mg}, 76 \%$ yield; $R_{f}=0.28$ (hexanes/AcOEt $=1 / 1) ;{ }^{1} \mathrm{H}$ NMR $\left(400 \mathrm{MHz}, \mathrm{CDCl}_{3}\right) \delta 6.51$ (dd, $J=12.4,6.5 \mathrm{~Hz}, 2 \mathrm{H}, \mathrm{Ar}$ ), 6.40 (dd, $J=6.5,2.4 \mathrm{~Hz}, 1 \mathrm{H}$, 
Ar), $3.48(\mathrm{dd}, J=6.5,2.4 \mathrm{~Hz}, 2 \mathrm{H}), 3.40(\mathrm{dd}, J=6.5,2.4 \mathrm{~Hz}$, $2 \mathrm{H}), 2.08(\mathrm{~s}, 3 \mathrm{H}, \mathrm{Me}) ;{ }^{13} \mathrm{C}$ NMR $\left(100 \mathrm{MHz}, \mathrm{CDCl}_{3}\right) \delta 133.1$, 131.6, 122.1, 120.3, 117.9, 112.8, 41.7, 41.1, 16.9.

6-Methyl-1,2,3,4-tetrahydroquinoxaline (2b). ${ }^{16}$ 6-Methyl3,4-dihydro-1H-quinoxalin-2-one $1 \mathbf{l b}(100 \mathrm{mg}, 0.60 \mathrm{mmol})$, lithium aluminum hydride $(200 \mathrm{mg}, 5.30 \mathrm{mmol})$, and dry $\mathrm{THF} /$ dry diethyl ether $=1: 2(15 \mathrm{~mL})$ were used: brown solid; $87 \mathrm{mg}, 93 \%$ yield; $R_{f}=0.37$ (hexanes $/ \mathrm{AcOEt}=1 / 1$ ); mp 99.1$102.2{ }^{\circ} \mathrm{C}$ (lit. $\left.100-102{ }^{\circ} \mathrm{C}\right) ;{ }^{16} \mathrm{H}$ NMR $\left(400 \mathrm{MHz}, \mathrm{CDCl}_{3}\right) \delta$ $6.41(\mathrm{~d}, J=8.0 \mathrm{~Hz}, 2 \mathrm{H}, \mathrm{Ar}), 6.32(\mathrm{~s}, 1 \mathrm{H}, \mathrm{Ar}), 3.38(\mathrm{~s}, 3 \mathrm{H}), 3.38$ (brs, $2 \mathrm{H}, \mathrm{NH}), 2.17$ (s, 3H, Me); ${ }^{13} \mathrm{C}$ NMR (100 MHz, $\left.\mathrm{CDCl}_{3}\right) \delta 133.7,131.1,128.3,119.0,115.4,114.9,41.5,41.5$, 20.7.

(S)-2-Methyl-1,2,3,4-tetrahydroquinoxaline (2c). ${ }^{11,17}$ (S)3-Methyl-3,4-dihydro-1H-quinoxalin-2-one 1c $(403 \mathrm{mg}, 2.50$ $\mathrm{mmol})$, lithium aluminum hydride $(840 \mathrm{mg}, 22.0 \mathrm{mmol})$, and dry THF $(80 \mathrm{~mL})$ were used: brown solid; $360 \mathrm{mg}, 98 \%$ yield; $R_{f}=0.28$ (hexanes $/ \mathrm{AcOEt}=4 / 1$ ); $\mathrm{mp} 62.0-65.2{ }^{\circ} \mathrm{C}$ (lit. 88.1$\left.89.5^{\circ} \mathrm{C}\right) ;^{8}[\alpha]_{\mathrm{D}}^{19}=-23.8(c 0.22, \mathrm{EtOH})\left(\right.$ lit. $[\alpha]_{\mathrm{D}}^{25}=-33.8(c$ 1.06, EtOH) $) ;{ }^{17}{ }^{1} \mathrm{H}$ NMR $\left(400 \mathrm{MHz}, \mathrm{CDCl}_{3}\right) \delta 6.61-6.55(\mathrm{~m}$, $2 \mathrm{H}, \mathrm{Ar}), 6.53-6.45(\mathrm{~m}, 2 \mathrm{H}, \mathrm{Ar}), 3.57(\mathrm{brs}, 1 \mathrm{H}, \mathrm{NH}), 3.50(\mathrm{t}, J$ $=6.1 \mathrm{~Hz}, 1 \mathrm{H}), 3.30(\mathrm{dd}, J=10.8,2.2 \mathrm{~Hz}, 1 \mathrm{H}), 3.03(\mathrm{t}, J=9.4$ $\mathrm{Hz}, 1 \mathrm{H}), 1.18(\mathrm{~d}, J=6.1 \mathrm{~Hz}, 3 \mathrm{H}, \mathrm{Me}) ;{ }^{13} \mathrm{C}$ NMR $(100 \mathrm{MHz}$, $\left.\mathrm{CDCl}_{3}\right) \delta 133.5,133.1,118.6(2 \mathrm{C}), 114.4,114.4,48.2,45.6$, 19.8 .

dl-2-Ethyl-1,2,3,4-tetrahydroquinoxaline (2d). ${ }^{11}$ 3-Ethyl3,4-dihydro-1H-quinoxalin-2-one $1 \mathrm{dd}(484 \mathrm{mg}, 2.70 \mathrm{mmol}$ ), lithium aluminum hydride ( $910 \mathrm{mg}, 24.2 \mathrm{mmol}$ ), and dry THF $(45 \mathrm{~mL})$ were used: orange solid; $434 \mathrm{mg}, 97 \%$ yield; $R_{f}=0.33$ (hexanes/AcOEt $=4 / 1$ ); mp 67.0-68.0 ${ }^{\circ} \mathrm{C}$ (lit. 67.9-69.2 $\left.{ }^{\circ} \mathrm{C}\right) ;{ }^{8}{ }^{1} \mathrm{H} \mathrm{NMR}\left(400 \mathrm{MHz}, \mathrm{CDCl}_{3}\right) \delta 6.60-6.54(\mathrm{~m}, 2 \mathrm{H}, \mathrm{Ar})$, 6.51-6.46 (m, 2H, Ar), 3.64 (brs, $1 \mathrm{H}, \mathrm{NH}), 3.37$ (dd, $J=10.5$, $2.9 \mathrm{~Hz}, 1 \mathrm{H}), 3.28(\mathrm{dq}, J=7.2,2.9 \mathrm{~Hz}, 1 \mathrm{H}), 3.06(\mathrm{dd}, J=10.5$, $7.2 \mathrm{~Hz}, 1 \mathrm{H}$ ), 1.52 (quint, $\left.J=7.2 \mathrm{~Hz}, 2 \mathrm{H}, \mathrm{CH}_{2}\right), 1.00(\mathrm{t}, J=7.6$ $\mathrm{Hz}, 3 \mathrm{H}, \mathrm{Me}) ;{ }^{13} \mathrm{C}$ NMR $\left(100 \mathrm{MHz}, \mathrm{CDCl}_{3}\right) \delta 133.5,133.4$, 118.7, 118.5, 114.4, 114.4, 51.7, 46.3, 27.1, 10.0 .

(S)-2,5-Dimethyl-1,2,3,4-tetrahydroquinoxaline (2e). (S)3,8-Dimethyl-3,4-dihydro-1H-quinoxalin-2-one 1 e $(400 \mathrm{mg}$, $2.30 \mathrm{mmol}$ ), lithium aluminum hydride $(603 \mathrm{mg}, 16.0$ mmol), and dry THF ( $40 \mathrm{~mL})$ were used: orange liquid; 335 $\mathrm{mg}, 91 \%$ yield; $R_{f}=0.38$ (hexanes $/$ AcOEt $\left.=2 / 1\right) ;[\alpha]_{\mathrm{D}}^{22}=$ $+6.52\left(\right.$ c $\left.0.29, \mathrm{CHCl}_{3}\right) ;{ }^{1} \mathrm{H}$ NMR $\left(400 \mathrm{MHz}, \mathrm{CDCl}_{3}\right) \delta 6.53(\mathrm{~d}$, $J=6.8 \mathrm{~Hz}, 1 \mathrm{H}, \mathrm{Ar}), 6.49(\mathrm{~d}, J=6.8 \mathrm{~Hz}, 1 \mathrm{H}, \mathrm{Ar}), 6.40(\mathrm{dd}, J=$ 6.8, $2.4 \mathrm{~Hz}, 1 \mathrm{H}, \mathrm{Ar}), 3.53-3.42(\mathrm{~m}, 1 \mathrm{H}), 3.47$ (brs, $1 \mathrm{H}, \mathrm{NH})$, $3.38(\mathrm{dd}, J=10.8,2.8 \mathrm{~Hz}, 1 \mathrm{H}), 3.06(\mathrm{dd}, J=10.8,8.3 \mathrm{~Hz}, 1 \mathrm{H})$, $2.08(\mathrm{~s}, 3 \mathrm{H}, \mathrm{Me}), 1.17(\mathrm{~d}, J=6.3 \mathrm{~Hz}, 3 \mathrm{H}, \mathrm{Me}) ;{ }^{13} \mathrm{C} \mathrm{NMR}(100$ $\left.\mathrm{MHz}, \mathrm{CDCl}_{3}\right) \delta 133.1,131.1,121.9,120.2,117.9,112.6,48.5$, 45.4, 19.8, 17.0; IR $(\mathrm{NaCl}) \nu$ 3373, 2962, 2854, 1597, 1493, 1299, 1171, 966, $757 \mathrm{~cm}^{-1}$; HRMS (FAB) $\mathrm{m} / z[\mathrm{M}+\mathrm{H}]^{+}$calcd for $\mathrm{C}_{10} \mathrm{H}_{15} \mathrm{~N}_{2}$ 163.1236, found 163.1209.

(S)-2,7-Dimethyl-1,2,3,4-tetrahydroquinoxaline (2f). (S)3,6-Dimethyl-3,4-dihydro-1H-quinoxalin-2-one if $(795 \mathrm{mg}$, $2.50 \mathrm{mmol})$, lithium aluminum hydride $(1.31 \mathrm{~g}, 36.0 \mathrm{mmol})$, and dry THF $(80 \mathrm{~mL})$ were used: brown solid; $677 \mathrm{mg}, 93 \%$ yield; $R_{f}=0.33$ (hexanes $/ \mathrm{AcOEt}=2 / 1$ ); $\mathrm{mp} 50.6-52.4{ }^{\circ} \mathrm{C}$; $[\alpha]_{\mathrm{D}}^{22}=-17.44\left(\right.$ c $\left.0.22, \mathrm{CHCl}_{3}\right) ;{ }^{1} \mathrm{H}$ NMR $\left(400 \mathrm{MHz}, \mathrm{CDCl}_{3}\right)$ $\delta 6.43(\mathrm{~d}, J=7.8 \mathrm{~Hz}, 1 \mathrm{H}, \mathrm{Ar}), 6.39(\mathrm{~d}, J=7.8 \mathrm{~Hz}, 1 \mathrm{H}, \mathrm{Ar}), 6.33$ $(\mathrm{s}, 1 \mathrm{H}, \mathrm{Ar}), 3.45(\mathrm{brs}, 1 \mathrm{H}, \mathrm{NH}), 3.29\left(\mathrm{~d}, J=9.8 \mathrm{~Hz}, 2 \mathrm{H}, \mathrm{CH}_{2}\right)$, $3.00(\mathrm{t}, J=9.8 \mathrm{~Hz}, 1 \mathrm{H}, \mathrm{NH}), 2.17(\mathrm{~s}, 3 \mathrm{H}, \mathrm{Me}), 1.17(\mathrm{~d}, J=6.1$ $\mathrm{Hz}, 3 \mathrm{H}, \mathrm{Me}) ;{ }^{13} \mathrm{C}$ NMR $\left(100 \mathrm{MHz}, \mathrm{CDCl}_{3}\right) \delta 133.6,130.6$, 128.3, 119.0, 115.2, 114.7, 48.4, 45.9, 20.6, 19.9; IR (KBr) $\nu$ $3350,3305,2953,2852,1593,1523,1354,1301,848,800$ $\mathrm{cm}^{-1}$; HRMS (FAB) $\mathrm{m} / z[\mathrm{M}+\mathrm{H}]^{+}$calcd for $\mathrm{C}_{10} \mathrm{H}_{15} \mathrm{~N}_{2}$ 163.1235, found 163.1261 .

(S)-2,6-Dimethyl-1,2,3,4-tetrahydroquinoxaline (2g). (S)3,7-Dimethyl-3,4-dihydro-1 $\mathrm{H}$-quinoxalin-2-one $1 \mathrm{~g}(400 \mathrm{mg}$, $2.20 \mathrm{mmol}$ ), lithium aluminum hydride (603 $\mathrm{mg}, 16.0$ $\mathrm{mmol})$, and dry THF $(40 \mathrm{~mL})$ were used: yellow solid; 256 $\mathrm{mg}, 69 \%$ yield; $R_{f}=0.35$ (hexanes/AcOEt $=2 / 1$ ); $\mathrm{mp} 85.2-$ $87.2^{\circ} \mathrm{C} ;[\alpha]_{\mathrm{D}}^{22}=-7.75\left(\mathrm{c} 0.22, \mathrm{CHCl}_{3}\right) ;{ }^{1} \mathrm{H}$ NMR $(400 \mathrm{MHz}$, $\left.\mathrm{CDCl}_{3}\right) \delta 6.43-6.36(\mathrm{~m}, 2 \mathrm{H}, \mathrm{Ar}), 6.33(\mathrm{~s}, 1 \mathrm{H}, \mathrm{Ar}), 3.46(\mathrm{t}, J=$ $6.1 \mathrm{~Hz}, 1 \mathrm{H}), 3.29(\mathrm{dd}, J=10.8,2.4 \mathrm{~Hz}, 2 \mathrm{H}), 3.02(\mathrm{t}, J=8.5 \mathrm{~Hz}$, $1 \mathrm{H}), 2.17(\mathrm{~s}, 3 \mathrm{H}, \mathrm{Me}), 1.17(\mathrm{~d}, J=6.3 \mathrm{~Hz}, 3 \mathrm{H}, \mathrm{Me}) ;{ }^{13} \mathrm{C} \mathrm{NMR}$ $\left(100 \mathrm{MHz}, \mathrm{CDCl}_{3}\right) \delta 133.2,131.0,128.2,119.0,115.1,114.6$, 48.3, 45.8, 20.6, 19.8; IR (KBr) $\nu 3364,3329$, 2960, 2912, 2855, $1602,1522,1299,1171,867,800 \mathrm{~cm}^{-1}$; HRMS (FAB) $\mathrm{m} / z$ [M $+\mathrm{H}]^{+}$calcd for $\mathrm{C}_{10} \mathrm{H}_{15} \mathrm{~N}_{2}$ 163.1235, found 163.1214.

(S)-2,8-Dimethyl-1,2,3,4-tetrahydroquinoxaline (2h). (S)3,5-Dimethyl-3,4-dihydro-1H-quinoxalin-2-one $\mathbf{1 h}(100 \mathrm{mg}, 0.5$ $\mathrm{mmol})$, lithium aluminum hydride $(133 \mathrm{mg}, 3.5 \mathrm{mmol})$, and dry THF $(10 \mathrm{~mL})$ were used: yellow liquid; $65 \mathrm{mg}, 85 \%$ yield; $R_{f}=0.39$ (hexanes/AcOEt $\left.=3 / 1\right) ;[\alpha]_{\mathrm{D}}^{22}=-1.07(c 0.34$, $\left.\mathrm{CHCl}_{3}\right) ;{ }^{1} \mathrm{H}$ NMR $\left(400 \mathrm{MHz}, \mathrm{CDCl}_{3}\right) \delta 6.55-6.43(\mathrm{~m}, 2 \mathrm{H}$, $\mathrm{Ar}), 6.41(\mathrm{dd}, J=6.5,2.7 \mathrm{~Hz}, 1 \mathrm{H}, \mathrm{Ar}), 3.60-3.50(\mathrm{~m}, 1 \mathrm{H}), 3.30$ (dd, $J=10.4,2.9 \mathrm{~Hz}, 1 \mathrm{H}), 3.02(\mathrm{dd}, J=10.4,8.0 \mathrm{~Hz}, 1 \mathrm{H}), 2.09$ $(\mathrm{s}, 3 \mathrm{H}, \mathrm{Me}), 1.22(\mathrm{~d}, J=6.3 \mathrm{~Hz}, 3 \mathrm{H}, \mathrm{Me}) ;{ }^{13} \mathrm{C}$ NMR $(100$ $\left.\mathrm{MHz}, \mathrm{CDCl}_{3}\right) \delta 132.6,131.5,121.7,120.3,117.9,112.6,48.0$, 46.0, 20.1, 16.9; IR ( NaCl) $\nu ~ 3379,3965,2854,1598,1491$, $1298,1174,762 \mathrm{~cm}^{-1}$; HRMS (FAB) $\mathrm{m} / z[\mathrm{M}+\mathrm{H}]^{+}$calcd for $\mathrm{C}_{10} \mathrm{H}_{15} \mathrm{~N}_{2}$ 163.1236, found 163.1210 .

1-Methyl-1,2,3,4-tetrahydroquinoxaline (2i). ${ }^{18}$ 4-Methyl3,4-dihydro-1H-quinoxalin-2-one 1 i $(530 \mathrm{mg}, 3.2 \mathrm{mmol})$, lithium aluminum hydride $(869 \mathrm{mg}, 23.0 \mathrm{mmol})$, and dry THF $\left(50 \mathrm{~mL}\right.$ ) were used: orange liquid; $396 \mathrm{mg}, 82 \%$ yield; $R_{f}$ $=0.34($ hexanes $/ \mathrm{AcOEt}=4 / 1) ;{ }^{1} \mathrm{H}$ NMR $\left(400 \mathrm{MHz}, \mathrm{CDCl}_{3}\right)$ $\delta 6.67(\mathrm{dt}, J=7.6,1.5 \mathrm{~Hz}, 1 \mathrm{H}, \mathrm{Ar}), 6.61-6.54(\mathrm{~m}, 2 \mathrm{H}, \mathrm{Ar})$, $6.47(\mathrm{dd}, J=7.6,1.5 \mathrm{~Hz}, 1 \mathrm{H}, \mathrm{Ar}), 3.50-3.45(\mathrm{~m}, 2 \mathrm{H}), 3.29-$ $3.24(\mathrm{~m}, 2 \mathrm{H}), 2.86(\mathrm{~s}, 3 \mathrm{H}, \mathrm{Me}) ;{ }^{13} \mathrm{C} \mathrm{NMR}\left(100 \mathrm{MHz}, \mathrm{CDCl}_{3}\right)$ $\delta$ 136.2, 134.2, 118.7, 118.2, 113.6, 111.7, 49.9, 41.3, 39.1.

(S)-1,2,3,4-Tetrahydro-2-(hydroxymethyl)quinoxaline (2j). ${ }^{19}$ (S)-3-Hydroxymethyl-3,4-dihydro-1H-quinoxalin-2-one 1 j $(0.8 \mathrm{~g}, 4.5 \mathrm{mmol})$, lithium aluminum hydride $(1.2 \mathrm{~g}, 31$ $\mathrm{mmol})$, and dry THF $(80 \mathrm{~mL})$ were used: dark orange liquid; $587 \mathrm{mg}$, 79\% yield; $R_{f}=0.32$ (hexanes $/ \mathrm{AcOEt}=1 / 4$ ); $[\alpha]_{\mathrm{D}}^{22}=$ $-35.75\left(c 0.31, \mathrm{CHCl}_{3}\right)\left(\right.$ lit. $[\alpha]_{\mathrm{D}}^{20}=-12.6\left(c 0.40, \mathrm{CHCl}_{3}\right) ;{ }^{19}$ ${ }^{1} \mathrm{H}$ NMR $\left(400 \mathrm{MHz}, \mathrm{CDCl}_{3}\right) \delta 6.64-6.56(\mathrm{~m}, 2 \mathrm{H}, \mathrm{Ar}), 6.55-$ $6.48(\mathrm{~m}, 2 \mathrm{H}, \mathrm{Ar}), 3.66(\mathrm{dd}, J=10.8,4.8 \mathrm{~Hz}, 1 \mathrm{H}), 3.56(\mathrm{dd}, J$ $=10.8,6.8 \mathrm{~Hz}, 1 \mathrm{H}), 3.53-3.46(\mathrm{~m}, 1 \mathrm{H}), 3.50(\mathrm{brs}, 2 \mathrm{H}, \mathrm{NH})$, $3.28(\mathrm{dd}, J=10.8,3.2 \mathrm{~Hz}, 1 \mathrm{H}), 3.16(\mathrm{dd}, J=10.8,6.0 \mathrm{~Hz}, 1 \mathrm{H})$; ${ }^{13} \mathrm{C}$ NMR $\left(100 \mathrm{MHz}, \mathrm{CDCl}_{3}\right) \delta 133.1,132.9,119.2,118.7$, 114.9, 114.7, 64.6, 51.5, 42.6.

5,7-Dimethyl-1,2,3,4-tetrahydroquinoxaline (2k). 6,8-Dimethyl-1H-quinoxalin-2-one $1 \mathbf{k}(471 \mathrm{mg}, 2.70 \mathrm{mmol})$, lithium aluminum hydride $(720 \mathrm{mg}, 19.0 \mathrm{mmol})$, and dry THF (47 $\mathrm{mL}$ ) were used: brown solid; $360 \mathrm{mg}, 82 \%$ yield; $R_{f}=0.31$ (hexanes/AcOEt $=1 / 1)$; mp 81.3-82.9 ${ }^{\circ} \mathrm{C} ;{ }^{1} \mathrm{H}$ NMR (400 $\left.\mathrm{MHz}, \mathrm{CDCl}_{3}\right) \delta 6.33$ (s, 1H, Ar), $6.24(\mathrm{~s}, 1 \mathrm{H}, \mathrm{Ar}), 3.49-3.42$ $(\mathrm{m}, 3 \mathrm{H}), 3.42-3.32(\mathrm{~m}, 3 \mathrm{H}), 2.15(\mathrm{~s}, 3 \mathrm{H}, \mathrm{Me}), 2.06(\mathrm{~s}, 3 \mathrm{H}$, $\mathrm{Me}) ;{ }^{13} \mathrm{C}$ NMR $\left(100 \mathrm{MHz}, \mathrm{CDCl}_{3}\right) \delta 133.3,129.0,127.6$, 122.5, 121.0, 113.5, 41.8, 41.4, 20.5, 16.8; IR ( $\mathrm{KBr}) \nu$ 3247, 2923, 1592, 1488, 1347, 1243, 1130, 830, $684 \mathrm{~cm}^{-1}$; HRMS (FAB) $m / z[M+H]^{+}$calcd for $\mathrm{C}_{10} \mathrm{H}_{15} \mathrm{~N}_{2}$ 163.1236, found 163.1239.

(R)-2-Methyl-1,2,3,4-tetrahydroquinoxaline (2l). ${ }^{20}$ (R)-3Methyl-3,4-dihydro-1H-quinoxalin-2-one $11(200 \mathrm{mg}, 1.20$ 
$\mathrm{mmol}$ ), lithium aluminum hydride $(328 \mathrm{mg}, 8.60 \mathrm{mmol})$, and dry THF $(20 \mathrm{~mL})$ were used: dark brown solid; $142 \mathrm{mg}, 78 \%$ yield; $R_{f}=0.35$ (hexanes $/ \mathrm{AcOEt}=2 / 1$ ); $\mathrm{mp} 66.3-69.1{ }^{\circ} \mathrm{C}$ (lit. mp 71-72 $\left.{ }^{\circ} \mathrm{C}\right) ;{ }^{17}[\alpha]_{\mathrm{D}}^{19}=+4.09\left(\right.$ c $\left.0.22, \mathrm{CH}_{2} \mathrm{Cl}_{2}\right)\left(\right.$ lit. $[\alpha]_{\mathrm{D}}^{20}=$ $\left.+3.70\left(c 0.50, \mathrm{CH}_{2} \mathrm{Cl}_{2}\right)\right) ;{ }^{20}{ }^{1} \mathrm{H}$ NMR $\left(400 \mathrm{MHz}, \mathrm{CDCl}_{3}\right) \delta$ 6.61-6.55 (m, 2H, Ar), 6.53-6.47 (m, 2H, Ar), 3.58 (brs, $1 \mathrm{H}$, $\mathrm{NH}), 3.55-3.42(\mathrm{~m}, 1 \mathrm{H}), 3.30(\mathrm{dd}, J=10.7,2.9 \mathrm{~Hz}, 1 \mathrm{H}), 3.02$ (dd, $J=10.7,8.2 \mathrm{~Hz}, 1 \mathrm{H}), 1.18(\mathrm{~d}, J=6.3 \mathrm{~Hz}, 3 \mathrm{H}, \mathrm{Me}) ;{ }^{13} \mathrm{C}$ NMR $\left(100 \mathrm{MHz}, \mathrm{CDCl}_{3}\right) \delta 133.5,133.1,118.6$ (2C), 114.4, 114.4, 48.2, 45.7, 19.8 .

(R)-2,7-Dimethyl-1,2,3,4-tetrahydroquinoxaline (2m). (R)3,6-Dimethyl-3,4-dihydro-1H-quinoxalin-2-one $1 \mathrm{~m}(200 \mathrm{mg}$, $1.10 \mathrm{mmol})$, lithium aluminum hydride $(302 \mathrm{mg}, 7.90 \mathrm{mmol})$, and dry THF $(20 \mathrm{~mL})$ were used: brown solid; $122 \mathrm{mg}, 66 \%$ yield; $R_{f}=0.36$ (hexanes $/ \mathrm{AcOEt}=2 / 1$ ); $\mathrm{mp} 44.2-45.4{ }^{\circ} \mathrm{C}$; $[\alpha]_{\mathrm{D}}^{22}=+8.17\left(c 0.22, \mathrm{CHCl}_{3}\right) ;{ }^{1} \mathrm{H} \mathrm{NMR}\left(400 \mathrm{MHz}, \mathrm{CDCl}_{3}\right) \delta$ $6.43(\mathrm{~d}, J=8.0 \mathrm{~Hz}, 1 \mathrm{H}, \mathrm{Ar}), 6.38(\mathrm{~d}, J=8.0 \mathrm{~Hz}, 1 \mathrm{H}, \mathrm{Ar}), 6.32$ (s, 1H, Ar), 3.56-3.44 (m, 1H), $2.78(\mathrm{dd}, J=10.4,2.6 \mathrm{~Hz}$, $1 \mathrm{H}), 2.99$ (dd, $J=10.4,8.4 \mathrm{~Hz}, 1 \mathrm{H}), 2.17$ (s, 3H, Me), 1.17 (d, $J=6.4 \mathrm{~Hz}, 3 \mathrm{H}, \mathrm{Me}) ;{ }^{13} \mathrm{C} \mathrm{NMR}\left(100 \mathrm{MHz}, \mathrm{CDCl}_{3}\right) \delta 133.6$, 130.6, 128.3, 119.0, 115.1, 114.7, 48.4, 45.9, 20.6, 19.9; IR $(\mathrm{KBr})$ ע 3350, 3304, 2955, 2913, 2852, 1598, 1522, 1363, 1303, $871,802 \mathrm{~cm}^{-1}$; HRMS (FAB) $\mathrm{m} / z[\mathrm{M}+\mathrm{H}]^{+}$calcd for $\mathrm{C}_{10} \mathrm{H}_{15} \mathrm{~N}_{2}$ 163.1235, found 163.1220.

(R)-2,5-Dimethyl-1,2,3,4-tetrahydroquinoxaline (2n). (R)3,8-Dimethyl-3,4-dihydro-1H-quinoxalin-2-one $1 \mathrm{n}(200 \mathrm{mg}$, $1.10 \mathrm{mmol}$ ), lithium aluminum hydride (302 $\mathrm{mg}, 7.90$ $\mathrm{mmol})$, and dry THF (20 mL) were used: yellow liquid; 335 mg, 95\% yield; $R_{f}=0.38$ (hexanes $/$ AcOEt $=2 / 1$ ); $[\alpha]_{\mathrm{D}}^{21}=$ -9.83 (c 0.28, $\mathrm{CHCl}_{3}$ ); ${ }^{1} \mathrm{H}$ NMR $\left(400 \mathrm{MHz}, \mathrm{CDCl}_{3}\right) \delta 6.53$ $(\mathrm{d}, J=6.8 \mathrm{~Hz}, 1 \mathrm{H}, \mathrm{Ar}), 6.49(\mathrm{~d}, J=6.8 \mathrm{~Hz}, 1 \mathrm{H}, \mathrm{Ar}), 6.40(\mathrm{dd}, J$ $=6.8,2.2 \mathrm{~Hz}, 1 \mathrm{H}, \mathrm{Ar}), 3.53-3.43(\mathrm{~m}, 1 \mathrm{H}), 3.48$ (brs, $1 \mathrm{H}, \mathrm{NH})$, $3.39(\mathrm{dd}, J=10.7,2.8 \mathrm{~Hz}, 1 \mathrm{H}), 3.06(\mathrm{dd}, J=10.7,8.3 \mathrm{~Hz}, 1 \mathrm{H})$, 2.08 (s, 3H, Me), 1.17 (d, $J=6.3 \mathrm{~Hz}, 3 \mathrm{H}, \mathrm{Me}) ;{ }^{13} \mathrm{C}$ NMR $(100$ $\left.\mathrm{MHz}, \mathrm{CDCl}_{3}\right) \delta 133.1,131.1,121.9,120.3,117.9,112.6,48.5$, 45.4, 19.8, 17.0; IR $(\mathrm{NaCl}) \nu$ 3366, 2965, 2853, 1596, 1490, 1294, 1171, 966, $762 \mathrm{~cm}^{-1}$; HRMS (FAB) $m / z[\mathrm{M}+\mathrm{H}]^{+}$calcd for $\mathrm{C}_{10} \mathrm{H}_{15} \mathrm{~N}_{2}$ 163.1235, found 163.1226.

(R)-2,6-Dimethyl-1,2,3,4-tetrahydroquinoxaline (2o). (R)3,7-Dimethyl-3,4-dihydro-1H-quinoxalin-2-one $10(350 \mathrm{mg}$, $2.00 \mathrm{mmol}$ ), lithium aluminum hydride (528 mg, 14.0 mmol), and dry THF (35 mL) were used: yellow solid; 241 $\mathrm{mg}, 74 \%$ yield; $R_{f}=0.38$ (hexanes $/ \mathrm{AcOEt}=2 / 1$ ); mp 101.9$106.6{ }^{\circ} \mathrm{C} ;[\alpha]_{\mathrm{D}}^{23}=+7.36\left(c 0.27, \mathrm{CHCl}_{3}\right) ;{ }^{1} \mathrm{H} \mathrm{NMR}(400 \mathrm{MHz}$, $\left.\mathrm{CDCl}_{3}\right) \delta 6.44-6.36(\mathrm{~m}, 2 \mathrm{H}, \mathrm{Ar}), 6.33$ (s, 1H, Ar), 3.51-3.40 (m, $1 \mathrm{H}), 3.46$ (brs, $1 \mathrm{H}, \mathrm{NH}), 3.28(\mathrm{dd} J=10.6,2.9 \mathrm{~Hz}, 1 \mathrm{H})$, 3.01 (dd, $J=10.6,8.3 \mathrm{~Hz}, 1 \mathrm{H}), 2.17$ (s, 3H, Me), 1.17 (d, $J=$ $6.3 \mathrm{~Hz}, 3 \mathrm{H}, \mathrm{Me}) ;{ }^{13} \mathrm{C} \mathrm{NMR}\left(100 \mathrm{MHz}, \mathrm{CDCl}_{3}\right) \delta 133.2,131.0$, 128.2, 119.0, 115.1, 114.7, 48.3, 45.8, 20.6, 19.8; IR (KBr) $\nu$ 3367, 3326, 2961, 2911, 2853, 1603, 1522, 1298, 1170, 867, $799 \mathrm{~cm}^{-1}$; HRMS (FAB) $\mathrm{m} / z[\mathrm{M}+\mathrm{H}]^{+}$calcd for $\mathrm{C}_{10} \mathrm{H}_{15} \mathrm{~N}_{2}$ 163.1235, found 163.1226 .

General Procedure for Synthesis of the Quinoxalines. A suspension of 1,2,3,4-tetrahydroquinoxaline, $\mathrm{V}_{2} \mathrm{O}_{5}(2.5-3.0$ equiv), and silica gel in toluene was stirred at reflux temperature under $\mathrm{Ar}$ for $24 \mathrm{~h}$. The reaction mixture was cooled and filtered through a Celite plug using $\mathrm{CHCl}_{3}$. The solvents were removed in vacuo, and the residue was purified by silica gel column chromatography (eluent: hexanes/AcOEt) to afford the corresponding quinoxaline 3 .

5-Methylquinoxaline $(3 a)^{21}$ 5-Methyl-1,2,3,4-tetrahydroquinoxaline $2 \mathrm{a}(98 \mathrm{mg}, 0.66 \mathrm{mmol}), \mathrm{V}_{2} \mathrm{O}_{5}(300 \mathrm{mg}, 1.60$ $\mathrm{mmol})$, silica gel $(500 \mathrm{mg})$, and toluene $(5 \mathrm{~mL})$ were used: yellow liquid; $62 \mathrm{mg}$, $65 \%$ yield; $R_{f}=0.34$ (hexanes $/ \mathrm{AcOEt}=$ 9/1); ${ }^{1} \mathrm{H}$ NMR $\left(400 \mathrm{MHz}, \mathrm{CDCl}_{3}\right) \delta 8.85(\mathrm{dd}, J=6.2,1.8 \mathrm{~Hz}$, $2 \mathrm{H}), 7.95(\mathrm{dd}, J=8.2,0.7 \mathrm{~Hz}, 1 \mathrm{H}, \mathrm{Ar}), 7.67(\mathrm{t}, J=8.2 \mathrm{~Hz}, 1 \mathrm{H}$, Ar), 7.62 (d, $J=6.2 \mathrm{~Hz}, 1 \mathrm{H}, \mathrm{Ar}), 2.81(\mathrm{~s}, 3 \mathrm{H}, \mathrm{Me}) ;{ }^{13} \mathrm{C} \mathrm{NMR}$ $\left(100 \mathrm{MHz}, \mathrm{CDCl}_{3}\right) \delta 144.6,143.7,143.2,142.2,137.7,130.0$, 129.8, 127.4, 17.3.

6-Methylquinoxaline (3b). ${ }^{21}$ 6-Methyl-1,2,3,4-tetrahydroquinoxaline $2 \mathbf{b}(296 \mathrm{mg}, 2.00 \mathrm{mmol}), \mathrm{V}_{2} \mathrm{O}_{5}(900 \mathrm{mg}, 5.00$ $\mathrm{mmol})$, silica gel $(1.6 \mathrm{~g})$, and toluene $(12 \mathrm{~mL})$ were used: yellow liquid; $184 \mathrm{mg}, 64 \%$ yield; $R_{f}=0.28$ (hexanes $/ \mathrm{AcOEt}=$ 4/1); ${ }^{1} \mathrm{H}$ NMR (400 MHz, $\left.\mathrm{CDCl}_{3}\right) \delta 8.69(\mathrm{~d}, J=8.0 \mathrm{~Hz}, 2 \mathrm{H})$, $7.90(\mathrm{~d}, J=8.6 \mathrm{~Hz}, 1 \mathrm{H}, \mathrm{Ar}), 7.79$ (s, $1 \mathrm{H}, \mathrm{Ar}), 7.51$ (d, $J=8.6$ $\mathrm{Hz}, 1 \mathrm{H}, \mathrm{Ar}), 2.51$ (s, 3H, Me); ${ }^{13} \mathrm{C} \mathrm{NMR}\left(100 \mathrm{MHz}, \mathrm{CDCl}_{3}\right) \delta$ 144.8, 144.0, 143.0, 141.4, 140.6, 132.3, 128.9, 128.2, 21.7.

2-Methylquinoxaline (3c). ${ }^{21}$ 2-Methyl-1,2,3,4-tetrahydroquinoxaline $2 \mathrm{c}(222 \mathrm{mg}, 1.50 \mathrm{mmol}), \mathrm{V}_{2} \mathrm{O}_{5}(552 \mathrm{mg}, 3.00$ $\mathrm{mmol})$, silica gel $(1.2 \mathrm{~g})$, and toluene $(9 \mathrm{~mL})$ were used: dark orange liquid; $120 \mathrm{mg}, 55 \%$ yield; $R_{f}=0.30$ (hexanes $/ \mathrm{AcOEt}=$ 9/1); ${ }^{1} \mathrm{H}$ NMR (400 MHz, $\left.\mathrm{CDCl}_{3}\right) \delta 8.75$ (s, 1H), 8.07 (dd, $J$ $=7.8,1.7 \mathrm{~Hz}, 1 \mathrm{H}, \mathrm{Ar}), 8.02(\mathrm{dd}, J=7.8,1.7 \mathrm{~Hz}, 1 \mathrm{H}, \mathrm{Ar}), 7.73$ (dquint, $J=7.8,1.7 \mathrm{~Hz}, 1 \mathrm{H}), 2.78(\mathrm{~s}, 3 \mathrm{H}, \mathrm{Me}) ;{ }^{13} \mathrm{C}$ NMR $(100$ $\left.\mathrm{MHz}, \mathrm{CDCl}_{3}\right) \delta 153.7,146.0,142.0,140.9,130.0,129.1,128.9$, $128.6,22.5$.

2-Ethylquinoxaline (3d). ${ }^{22}$ 2-Ethyl-1,2,3,4-tetrahydroquinoxaline $2 \mathrm{~d}(162 \mathrm{mg}, 1.00 \mathrm{mmol}), \mathrm{V}_{2} \mathrm{O}_{5}(460 \mathrm{mg}, 2.50$ $\mathrm{mmol})$, silica gel $(0.8 \mathrm{~g})$, and toluene $(6 \mathrm{~mL})$ were used: pale orange liquid; $104 \mathrm{mg}, 69 \%$ yield; $R_{f}=0.40$ (hexanes $/ \mathrm{AcOEt}=$ 4/1); ${ }^{1} \mathrm{H}$ NMR $\left(400 \mathrm{MHz}, \mathrm{CDCl}_{3}\right) \delta 8.77(\mathrm{~s}, 1 \mathrm{H}), 8.06(\mathrm{dq}, J$ $=8.0,2.0 \mathrm{~Hz}, 2 \mathrm{H}, \mathrm{Ar}$ ), 7.73 (dquint, $J=8.0,1.6 \mathrm{~Hz}, 2 \mathrm{H}, \mathrm{Ar}$ ), $3.06(\mathrm{q}, J=7.6 \mathrm{~Hz}, 2 \mathrm{H}), 1.45(\mathrm{t}, J=7.6 \mathrm{~Hz}, 3 \mathrm{H}) ;{ }^{13} \mathrm{C} \mathrm{NMR}$ $\left(100 \mathrm{MHz}, \mathrm{CDCl}_{3}\right) \delta 158.5,145.5,142.1,141.2,129.9,129.1$, 128.9, 128.8, 29.6, 13.4 .

2,5-Dimethylquinoxaline (3e). ${ }^{23}$ 2,5-Dimethyl-1,2,3,4-tetrahydroquinoxaline $2 \mathrm{e}(162 \mathrm{mg}, 1.00 \mathrm{mmol}), \mathrm{V}_{2} \mathrm{O}_{5}(455 \mathrm{mg}, 2.50$ $\mathrm{mmol})$, silica gel $(0.8 \mathrm{~g})$, and toluene $(6 \mathrm{~mL})$ were used: orange liquid; $141 \mathrm{mg}, 89 \%$ yield; $R_{f}=0.37$ (hexanes $/$ AcOEt $=4 / 1$ ); ${ }^{1} \mathrm{H}$ NMR (400 MHz, $\mathrm{CDCl}_{3}$ ) $\delta 8.75(\mathrm{~s}, 1 \mathrm{H}), 7.85$ (d, $J=8.3$ $\mathrm{Hz}, 1 \mathrm{H}, \mathrm{Ar}), 7.63$ (t, $J=8.3 \mathrm{~Hz}, 1 \mathrm{H}, \mathrm{Ar}), 7.54(\mathrm{~d}, J=6.8 \mathrm{~Hz}$, $1 \mathrm{H}, \mathrm{Ar}), 2.79$ (s, 3H, Me), 2.78 (s, 3H, Me); ${ }^{13} \mathrm{C}$ NMR (100 $\left.\mathrm{MHz}, \mathrm{CDCl}_{3}\right) \delta 153.2,144.6,142.1,140.1,137.3,129.7,129.0$, $126.5,22.4,17.3$.

2,7-Dimethylquinoxaline (3f). ${ }^{23}$ 2,7-Dimethyl-1,2,3,4-tetrahydroquinoxaline $2 \mathrm{f}(252 \mathrm{mg}, 1.56 \mathrm{mmol}), \mathrm{V}_{2} \mathrm{O}_{5}(682 \mathrm{mg}, 3.75$ $\mathrm{mmol})$, silica gel $(1.2 \mathrm{~g})$, and toluene $(9 \mathrm{~mL})$ were used: pale orange solid; $194 \mathrm{mg}, 79 \%$ yield; $R_{f}=0.40$ (hexanes $/ \mathrm{AcOEt}=$ 2/1); mp 76.2-76.5 ${ }^{\circ} \mathrm{C}$ (lit. 79-80 $\left.{ }^{\circ} \mathrm{C}\right) ;{ }^{20}{ }^{1} \mathrm{H}$ NMR (400 $\left.\mathrm{MHz}, \mathrm{CDCl}_{3}\right) \delta 8.67(\mathrm{~s}, 1 \mathrm{H}), 7.95(\mathrm{~d}, J=8.5 \mathrm{~Hz}, 1 \mathrm{H}, \mathrm{Ar}), 7.78$ (s, $1 \mathrm{H}, \mathrm{Ar}), 7.53(\mathrm{dd}, J=8.5,1.7 \mathrm{~Hz}, 1 \mathrm{H}, \mathrm{Ar}), 2.76(\mathrm{~s}, 3 \mathrm{H}, \mathrm{Me})$, 2.59 (s, 3H, Me); ${ }^{13} \mathrm{C}$ NMR $\left(100 \mathrm{MHz}, \mathrm{CDCl}_{3}\right) \delta 153.6,145.1$, $142.1,140.5,139.4,131.2,128.6,127.5,22.6,21.8$.

2,6-Dimethylquinoxaline (3g). ${ }^{23}$ 2,6-Dimethyl-1,2,3,4-tetrahydroquinoxaline $2 \mathrm{~g}$ (163 $\mathrm{mg}, 1.00 \mathrm{mmol}), \mathrm{V}_{2} \mathrm{O}_{5}$ (545 mg, 3.00 $\mathrm{mmol})$, silica gel $(0.8 \mathrm{~g})$, and toluene $(6 \mathrm{~mL})$ were used: red solid; $122 \mathrm{mg}$, $77 \%$ yield; $R_{f}=0.40$ (hexanes $/$ AcOEt $=2 / 1$ ); $\mathrm{mp} 73.0-74.1{ }^{\circ} \mathrm{C}$ (lit. 74-75 $\left.{ }^{\circ} \mathrm{C}\right) ;{ }^{23}{ }^{1} \mathrm{H}$ NMR (400 MHz, $\left.\mathrm{CDCl}_{3}\right) \delta 8.69(\mathrm{~s}, 1 \mathrm{H}), 7.89(\mathrm{~d}, J=8.8 \mathrm{~Hz}, 1 \mathrm{H}, \mathrm{Ar}), 7.83(\mathrm{~s}$, $1 \mathrm{H}, \mathrm{Ar}$ ), 7.56 (dd, $J=8.8,2.0 \mathrm{~Hz}, 1 \mathrm{H}, \mathrm{Ar}), 2.75$ (s, 3H, Me), 2.58 (s, 3H, Me); ${ }^{13} \mathrm{C}$ NMR $\left(100 \mathrm{MHz}, \mathrm{CDCl}_{3}\right) \delta 152.8,145.9$, 141.0, 140.5, 139.3, 132.2, 128.1, 128.0, 22.4, 21.7.

2,8-Dimethylquinoxaline (3h). ${ }^{24}$ 2,8-Dimethyl-1,2,3,4-tetrahydroquinoxaline $2 \mathrm{~h}(81 \mathrm{mg}, 0.5 \mathrm{mmol}), \mathrm{V}_{2} \mathrm{O}_{5}(227 \mathrm{mg}, 1.25$ $\mathrm{mmol})$, silica gel $(0.4 \mathrm{~g})$, and toluene $(5 \mathrm{~mL})$ were used: pale yellow liquid; $61 \mathrm{mg}$, 77\% yield; $R_{f}=0.33$ (hexanes $/ \mathrm{AcOEt}=$ 
19/1); ${ }^{1} \mathrm{H}$ NMR (400 MHz, $\left.\mathrm{CDCl}_{3}\right) \delta 8.71(\mathrm{~s}, 1 \mathrm{H}), 7.92-7.87$ (m, 1H, Ar), 7.60-7.55 (m, 2H, Ar), 2.78 (s, 3H, Me), 2.77 (s, $3 \mathrm{H}, \mathrm{Me}) ;{ }^{13} \mathrm{C} \mathrm{NMR}\left(100 \mathrm{MHz}, \mathrm{CDCl}_{3}\right) \delta 152.6,145.5,141.3$, 141.0, 137.0, 130.0, 128.5, 127.0, 22.7, 17.2.

Quinoxaline-2-carbaldehyde (3j). ${ }^{25}$ 1,2,3,4-Tetrahydro-2(hydroxymethyl)quinoxaline $2 \mathrm{j}(116 \mathrm{mg}, 0.70 \mathrm{mmol}), \mathrm{V}_{2} \mathrm{O}_{5}$ (322 mg, $1.80 \mathrm{mmol})$, silica gel $(560 \mathrm{mg})$, and toluene $(5 \mathrm{~mL})$ were used: pale yellow solid; $12 \mathrm{mg}, 11 \%$ yield; $R_{f}=0.39$ (hexanes/AcOEt $=4 / 1)$; mp 98.1-99.6 ${ }^{\circ} \mathrm{C}\left(\right.$ lit. $\left.98-100{ }^{\circ} \mathrm{C}\right) ;^{25}$ ${ }^{1} \mathrm{H}$ NMR (400 MHz, $\left.\mathrm{CDCl}_{3}\right) \delta 10.30(\mathrm{~s}, 1 \mathrm{H}, \mathrm{CHO}), 9.44$ (s, $1 \mathrm{H}), 8.31-819$ (m, 2H, Ar), 8.00-7.87 (m, 2H, Ar); ${ }^{13} \mathrm{C}$ NMR $\left(100 \mathrm{MHz}, \mathrm{CDCl}_{3}\right) \delta 192.7,145.9,144.4,142.5,141.9,132.9$, $131.2,130.5,129.6$.

5,7-Dimethylquinoxaline (3k). 5,7-Dimethyl-1,2,3,4-tetrahydroquinoxaline $2 \mathrm{k}(168 \mathrm{mg}, 1.0 \mathrm{mmol}), \mathrm{V}_{2} \mathrm{O}_{5}(455 \mathrm{mg}, 2.50$ mmol), silica gel $(0.8 \mathrm{~g})$, and toluene $(6 \mathrm{~mL})$ were used: orange liquid; $130 \mathrm{mg}, 80 \%$ yield; $R_{f}=0.34$ (hexanes $/ \mathrm{AcOEt}=4 / 1$ ); ${ }^{1} \mathrm{H}$ NMR (400 MHz, $\left.\mathrm{CDCl}_{3}\right) \delta 8.78(\mathrm{~d}, J=2.0 \mathrm{~Hz}, 2 \mathrm{H}), 7.71$ (s, 1H, Ar), 7.28 (s, 1H, Ar), 2.77 (s, 3H, Me), 2.56 (s, 3H, $\mathrm{Me}) ;{ }^{13} \mathrm{C} \mathrm{NMR}\left(100 \mathrm{MHz}, \mathrm{CDCl}_{3}\right) \delta 144.5,143.3,142.8$, 140.7, 140.2, 137.0, 132.4, 126.1, 21.8, 17.2; IR ( NaCl) $\nu 3450$, 2920, 1619, 1492, 1355, 1082, 1032, $876 \mathrm{~cm}^{-1}$; HRMS (FAB) $m / z[\mathrm{M}+\mathrm{H}]^{+}$calcd for $\mathrm{C}_{10} \mathrm{H}_{11} \mathrm{~N}_{2}$ 159.0923, found 159.0932 .

Olfactory Evaluation. The olfactory properties of a series of quinoxalinones 1, 1,2,3,4-tetrahydroquinoxalines 2, and quinoxalines 3 were evaluated three times every 1 or 2 days. The evaluation was carried out between 11:00 and 12:00 a.m. before lunch to obtain the most sensitive periods. The five male panelists (35-50 years old) included a licensed smell examiner, one of the national licensees in Japan, an analyst of volatile components, and three flavorists. They had been trained in the objective evaluation and expression of odors for both business and academic research for over 15 years. They individually sniffed each compound kept in a tube $(0.8 \mathrm{~cm} \times 5 \mathrm{~cm})$. The amounts of the compounds were about $20 \mathrm{mg}$ each. Each panelist used as many odor-descriptive terms as possible. Common terms used by more than 2 persons were selected as the odorant attributes.

Biological Activity. Cell Culture. The human hepatocyte cell line HepG2 (ATCC, Manassas, VA) was cultured in DMEM with 5\% FBS, 100 units/mL streptomycin, and $100 \mu \mathrm{g} /$ $\mathrm{mL}$ penicillin, at $37{ }^{\circ} \mathrm{C}$ in a humidified $5 \% \mathrm{CO}_{2}$ atmosphere. Prior to the experiments, the cells were incubated overnight with serum-free DMEM. After treatment, the cells were washed twice with ice-cold phosphate-buffered saline (PBS) and lysed with radio-immunoprecipitation assay buffer containing $1 \%$ Triton X-100, the phosphatase inhibitor cocktail, and the protease inhibitor cocktail. The protein concentration of each lysate was determined using the BCA Protein Assay Reagent Kit (Nacalai Tesque, Kyoto, Japan).

Palmitate Treatment and Oil Red O Staining. To induce lipid overloading, HepG2 cells at the subconfluence were exposed to palmitate-containing media. Culture media containing palmitate were prepared, as previously described. ${ }^{5}$ Briefly, sodium palmitate was dissolved in $50 \% \mathrm{v} / \mathrm{v}$ ethanol, diluted in serum-free DMEM containing $1 \% \mathrm{w} / \mathrm{v}$ fatty acid free BSA, and incubated at $37{ }^{\circ} \mathrm{C}$ for $2 \mathrm{~h}$ with shaking. The control medium containing ethanol and BSA was similarly prepared. To evaluate the intracellular neutral lipid accumulation, Oil Red $\mathrm{O}$ staining was performed according to the published procedure with some modifications. ${ }^{5}$ Briefly, the cells were fixed in $10 \%$ paraformaldehyde in PBS for $10 \mathrm{~min}$, stained with $1.8 \mathrm{mg} / \mathrm{mL}$ Oil Red O (Sigma-Aldrich, St. Louis, MO) in a $60 \%$ aqueous isopropanol solution for $15 \mathrm{~min}$ at room temperature, and rinsed twice with $60 \%$ aqueous isopropanol and PBS. To quantify the cellular lipid content, the Oil Red $\mathrm{O}$ was extracted with $100 \%$ isopropanol, and then its absorbance at $490 \mathrm{~nm}$ was measured using a microplate reader. The cellular neutral lipid content was normalized to the protein concentration.

\section{ASSOCIATED CONTENT}

\section{Supporting Information}

The Supporting Information is available free of charge on the ACS Publications website at DOI: 10.1021/acsomega.7b00124.

Copies of NMR data of all compounds (PDF)

\section{AUTHOR INFORMATION}

\section{Corresponding Author}

*E-mail: tanimori@bioinfo.osakafu-u.ac.jp. Tel: +81 72254 9469. Fax: +81 722549469 .

\section{ORCID}

Shinji Tanimori: 0000-0002-7468-9870

Notes

The authors declare no competing financial interest.

\section{ACKNOWLEDGMENTS}

This work was financially supported by the Japan Society for the Promotion of Science KAKENHI Grant 25410051.

\section{REFERENCES}

(1) (a) Ajani, O. O. Eur. J. Med. Chem. 2014, 85, No. 688715. (b) Ferreira, S. R. A.; Franco, M. S. F.; Diniz, E. M. L. P.; Emery, F. S.; Clososki, G. C. Curr. Org. Synth. 2015, 12, 714-729. (c) Jeanguenat, A.; Durieux, P.; Edmunds, A. J. F.; Hall, R. G.; Hughes, D.; Loiseleur, O.; Pabba, J.; Stoller, A.; Trah, S.; Wenger, J.; Dutton, A.; Crossthwaite, A. Bioorg. Med. Chem. 2016, 24, 403-427. (d) Lu, J.; Zheng, Y.; Zhang, J. Phys. Chem. Chem. Phys. 2015, 17, 20014-20020.

(2) (a) Marterer, W.; Prikoszovich, W.; Wiss, J.; Prashad, M. Org. Process Res. Dev. 2003, 7, 318-323. (b) Flament, Y. J. Agric. Food Chem. 1967, 15, 15-23. (c) Vitzthum, G. O.; Werkhoff, P. J. Agric. Food Chem. 1975, 23, 510-516.

(3) Saari, R.; Torma, J.; Nevalainen, T. Bioorg. Med. Chem. 2011, 19, 939-950.

(4) Mallat, A.; Teixeira-Clerc, F.; Lotersztajn, S. J. Hepatol. 2013, 59, 891-896.

(5) Kamikubo, R.; Kai, K.; Tsuji-Naito, K.; Akagawa, M. Mol. Nutr. Food Res. 2016, 60, 2228-2242.

(6) (a) Mamedov, V. A.; Zhukova, N. A. Progress in Heterocyclic Chemistry; Elsevier: Oxford, 2013; Vol. 25, pp 1-45. (b) Bharagava, D.; Gopal, G. J. Pharm. Res. 2012, 5, 130-134.

(7) (a) Tanimori, S.; Kobayashi, Y.; Iesaki, Y.; Ozaki, Y.; Kirihata, M. Org. Biomol. Chem. 2012, 10, 1381-1387. (b) Tanimori, S.; Nishimura, T.; Kirihata, M. Bioorg. Med. Chem. Lett. 2009, 19, 4119-4121.

(8) Abou-Gharbia, M.; Freed, M. E.; McCaully, R. J.; Silver, P. J.; Wendt, R. L. J. Med. Chem. 1984, 27, 1743-1746.

(9) Karki, M.; Araujo, H. C.; Magolan, J. Synlett 2013, 24, 16751678.

(10) Tanimori, S.; Kashiwagi, H.; Nishimura, T.; Kirihata, M. Adv. Synth. Catal. 2010, 352, 2531-2537.

(11) Zhang, L.; Qiu, R.; Xue, X.; Pan, Y.; Xu, C.; Li, H.; Xu, L. Adv. Synth. Catal. 2015, 357, 3529-3537.

(12) Kim, Y.; Kang, K. H.; Choi, E. T.; Lee, M. H.; Park, Y. S. Bull. Korean Chem. Soc. 2007, 28, 325-328.

(13) Xun, L.; Donghua, W.; Jifeng, W.; Wenfang, X. Heterocycles 2005, 65, 2741-2751. 
(14) (a) Luo, X.; Chenard, E.; Martens, P.; Cheng, X. Y.; Tomaszewski, J. M. Org. Lett. 2010, 12, 3574-3577. (b) Castro, S.; Chicharro, R.; Arán, J. V. J. Chem. Soc., Perkin Trans. 1 2002, 790-802. (15) Wu, J.; Wang, C.; Tang, W.; Pettman, A.; Xiao, J. Chem. Eur. J. 2012, 18, 9525-9529.

(16) Wu, J.; Barnard, H. J.; Zhang, Y.; Talwar, D.; Robertson, M. C.; Xiao, J. Chem. Commun. 2013, 49, 7052-7054.

(17) Arai, N.; Saruwatari, Y.; Isobe, K.; Ohkuma, T. Adv. Synth. Catal. 2013, 355, 2769-2774.

(18) Qiao, J. X.; Wang, C. T.; Ruel, R.; Thibeault, C.; L'Heureux, A.; Schumacher, A. W.; Spronk, A. S.; Hiebert, S.; Bouthillier, G.; Lloyd, J.; Pi, Z.; Schnur, M. D.; Abell, M. L.; Hua, J.; Price, A. L.; Liu, E.; Wu, Q.; Steinbacher, E. T.; Bostwick, S. J.; Chang, M.; Zheng, J.; Gao, Q.; Ma, B.; McDonnell, A. P.; Huang, S. C.; Rehfuss, R.; Wexler, R. R.; Lam, S. Y. P. J. Med. Chem. 2013, 56, 9275-9295.

(19) Massacret, M.; Lhoste, P.; Sinou, D. Eur. J. Org. Chem. 1999, 1999, 129-134.

(20) Qin, J.; Chen, F.; Ding, Z.; He, M. Y.; Xu, L.; Fan, H. Q. Org. Lett. 2011, 13, 6568-6571.

(21) Wu, J.; Talwar, D.; Johnston, S.; Yan, M.; Xiao, J. Angew. Chem., Int. Ed. 2013, 52, 6983-6987.

(22) Tan, J.; Tang, W.; Sun, Y.; Jiang, Z.; Chen, F.; Xu, L.; Fan, Q.; Xiao, J. Tetrahedron 2011, 67, 6206-6213.

(23) Blaikley, W. C. D.; Currie, W. D.; Smith, M. D.; Watson, A. S. J. Chem. Soc., Perkin Trans. 1 1984, 367-369.

(24) McNab, H. J. Chem. Soc., Perkin Trans. 1 1984, 377-380.

(25) Jarikote, V. D.; Li, W.; Jiang, T.; Eriksson, A. L.; Murphy, V. P. Bioorg. Med. Chem. 2011, 19, 826-835. 